1 DEDEOĞLU, B., TAHERI, B., OKUMUS, F. \& GANNON, M. (2020).

2 Understanding the importance that consumers attach to social media sharing (ISMS): Scale

3 development and validation. Tourism Management.

4

\title{
Understanding the importance that consumers attach to social media sharing (ISMS):
} Scale development and validation

\begin{abstract}
In response to the increasing ubiquity of social media platforms, improved consumer choice, and technological progress, the importance of consumer-generated content (CGC) continues to grow for organizations marketing their destinations, products, and services to tourists. Yet, despite the importance tourists place on CGC and information shared via social media, there remains a lack of academic focus in this area. To address this gap, we use a rigorous multistep scale development procedure to create a scale centered on understanding the importance consumers attach to social media sharing (ISMS) from a tourists' perspective. Studies conducted across different contexts (Turkey and Scotland), comprising 1183 participants, were used to validate the newly developed ISMS scale. The scale indicates internal consistency and reliability, alongside construct and predictive validity. Directions for future research and the practical implications of the newly developed ISMS scale are discussed by way of conclusion.
\end{abstract}

\section{Keywords}

Consumer-generated content (CGC); social media; tourism; CGC types; importance of CGC; participant sharing; non-participant sharing 


\section{Introduction}

The benefits social media provides to consumers (e.g., easier access to information, more substantial product/service information from multiple perspectives, and access to enduser evaluations) serves to underpin the mediums' directing power (Kang, 2018). To this end, content shared via social media can influence tourists' decision-making in a number of ways, influencing their travel planning process by providing the reviews, virtual tours, and impartial information central to destination choice and itinerary development (Morosan \& Bowen, 2018). As such, travel websites and social media serve a dual purpose, underpinned by the symbiosis between providing a platform that allows potential and past consumers to respectively (i) gather and utilize information concerning tourism products and services, and (ii) share their own evaluations of destinations, tourism offerings, and services experienced prior (Perez-Vega, Taheri, Farrington, \& O’Gorman, 2018). As a result, consumers can have either a positive and negative impact on tourism services depending on the sentiment of the content, reviews, and opinions they share; with this influence intensified when a consistent narrative is demonstrated collectively by the community at large (Perez-Vega et al., 2018).

To this end, consumers have taken to sharing their opinions of travel destinations and experiences with gusto, with the number of reviews generated on third party, tourism-centric social media sites increasing significantly in recent years. For example, TripAdvisor users generated 200 million reviews in 2014, with this number rising to over 600 million in 2017. Moreover, estimates suggest that one in ten internet users have visited TripAdvisor.com, with the website boasting an average of 490 million users per month in 2018 (TripAdvisor, 2019). However, tourists intending to share their opinions and evaluations of destinations, sites, and experiences are not constrained to doing so on websites solely focused on showcasing and aggregating travel and tourism reviews. Instead, similar consumer-generated content (CGC) regularly emerges on more universal social media platforms, such as Instagram, Facebook, and Twitter (Lo et al., 2011; Mariani, Ek Styven, \& Ayeh, 2019). As a result, many marketers within the sector have shifted their attention from traditional media towards fostering engaged online communities underpinned by social media interactions (Liu, Li, North \& Yang, 2017). In response, tourism firms have increased the resources and expenses allocated to social media marketing, as CGC across social media platforms continues to prove increasingly important in terms of attracting potential consumers (Su, Huang, \& Hsu, 2018). As such, travel and tourism organizations require a greater understanding of CGC in order to stimulate more effective and efficient outcomes.

Social media differs from traditional media platforms as users generate the majority of the content. These users typically fall under two categories: firms and consumers (Xiang \& Gretzel, 2010). Many consider CGC as more organic, up-to-date, enjoyable, impartial, and reliable than firm-generated content (FGC). As such, CGC can influence the attitudes of other potential consumers (Gensler et al., 2013). Nonetheless, consumers generate content for different purposes (Kiecker \& Cowles, 2002; Shao, 2009; Chen et al., 2013). Some do so to feel socially accepted; to demonstrate their appreciation of a product, service, or experience; to engender respect or fame; or to exhibit their own knowledge and expertise (Chu \& Kim, 2011; Chen et al., 2013). Others create and share content to inform and help others (O’Hern \& Kahle, 2013). While sometimes explicit, individuals may also be unaware that they have created content at the behest of these intrinsic motives. Further, it is important to consider where content is shared; CGC on platforms linked to specific organizations typically serves a functional purpose, whereas CGC shared via personal social media accounts is more likely to serve a hedonic purpose (Grace-Farfaglia et al., 2006). As such, different types of content (shared on different platforms) are likely to influence the perceptions of potential consumers in different ways. Thus, the following questions underpin this study: i) can the type of, and importance attached to, CGC shared on social media differ? Moreover, ii) if differences are 
identified, can a suitable measurement instrument be developed to investigate the importance potential consumers attach to content shared on social media? As such, this study seeks to extend current discourse by providing a valid and reliable scale through which to measure the importance that potential consumers attach to social media sharing (ISMS) from a tourists' perspective. This scale encompasses the two core dimensions of social media sharing (IPS: Importance attached to participant sharing; INPS: Importance attached to non-participant sharing) as perceived by potential consumers.

In order to develop and validate the ISMS scale, it is first important to investigate and examine how CGC is manifest from a range of perspectives. CGC is an important antecedent in terms of directing the purchasing behaviors of potential consumers. The directing impact of CGC begins by raising consumer awareness of the products and experiences mentioned via shared content. In doing so, potential consumers may develop a degree of attachment to experiences vicariously through the content shared by others. This, in turn, may increase their level of interest towards those experiences. This process is reinforced by potential consumers' efforts to obtain further information on experiences of interest, and is finalized when they arrive at the 'purchasing' stage (Gursoy \& Gavcar, 2003). As such, for CGC to direct purchasing behavior, it must first play a role in raising consumer awareness of products, services, experiences, and brands. However, while CGC is recognized as an important determinant of brand awareness (Bruhn et al., 2012), the effectiveness of different types of CGC remains underexplored.

As such, CGC requires further examination. Current literature suggests that it is typically conceptualized in general terms, with ambiguity driven by the concession that CGC is generated under different circumstances and in different ways; consumers share content on both personal social media accounts and platforms aligned to specific organizations or brands (Kiecker \& Cowles, 2002). Further, consumers can generate content using third-party social media tools, further extending the complexity of the phenomenon. As CGC is generated across multiple platforms via different means, it is likely that the individuals who see, read, or hear this content, and who are influenced by it, may differ. However, CGC can be characterized by its emotional and functional appeal to other consumers (Chen et al., 2013). For example, tourists can typically only evaluate products and services during- or postconsumption; given the practical constraints of tourism (e.g. distance, cost, and risk), they rarely have the chance to 'try out' destinations and on-site experiences, products, and services therein prior to travel. Thus, tourism-related CGC provides potential consumers with the opportunity to access information otherwise inaccessible - shaping their opinions, perceptions, and expectations in the process (Zeng \& Gerritsen, 2014). Different social media content can therefore influence the travel decision-making process (Yoo \& Gretzel, 2012), with the analysis of different types of CGC likely to catalyze more effective and efficient curation of CGC for firms across the sector.

Yet, despite the importance of CGC for the tourism industry, research examining the different types of shared content and the level of importance attached by tourists to CGC on social media platforms has yet to receive sufficient academic attention. To address this gap, this study develops and validates a scale examining the importance that potential consumers attach to content shared via social media. The literature review summarizes extant studies on social media sharing, CGC as participant and non-participant sharing, and CGC as a driver of brand awareness. Subsequently, following Churchill (1979), a rigorous scale development process is used to validate the newly developed ISMS (Importance attached to Social Media Sharing) scale. Implications and conclusions are then provided, followed by suggestions for future research. 


\section{Literature Review}

\subsection{Social media and the importance of consumer-generated content}

Social media encourages and facilitates interaction, cooperation, and content sharing (Palmer \& Lewis, 2009). It takes various forms, including blogs, micro-blogs, social networks, online forums, media-sharing websites, and review websites (Malik, Dhir, \& Nieminen, 2016). Both firms and consumers generate content on many of these platforms (Xiang \& Gretzel, 2010). However, as potential consumers perceive CGC as more candid, impartial, and reliable than FGC (Herrero, Martin \& Hernández, 2015), it is pivotal for organizations to gain an understanding of how best to ensure that it emerges in a manner that does not damage their brand. Besides the significant role of CGC in encouraging potential consumers to engage with products, services, or experiences, the attractiveness and relevance of the content shared is also important (Chen et al., 2015).

CGC can direct purchasing behavior and influence potential consumers in various ways. This is consistent with social influence theories (e.g., social comparison and social contagion), which suggest that individuals adopt similar beliefs, attitudes, and behaviors to others through communication (i.e., contact with those they consider influential) (Bilgicer, Jedidi, Lehmann, \& Neslin, 2015). Miniard and Cohen (1983, p.171) argue that "to the extent consumers' behavior is influenced by concerns over what others might think of them or how others might act toward them as a function of their product choice and usage, the identification and separation of normative from personal reasons for preferring a product would appear to be quite useful". To this end, social comparison can also take place when individuals "are sensitive to social cues concerning their purchase and consumption behavior" (Bearden \& Rose, 1990, p.463); seeking the same products and experiences as those conspicuously consumed by influencers. Therefore, when shared by individuals with a degree of social influence, CGC can shape consumers' decision-making and purchasing processes (Mariani, Ek Styven, \& Ayeh, 2019). Further, in line with the elaboration likelihood model (ELM), potential consumers consider content created and shared on social media as a core component of the information evaluation process. For example, an individual who considers CGC as qualified, useful, and reliable, or who trusts the person sharing the content, may follow a peripheral consumption route. As outlined in ELM, the peripheral route for processing information can shorten the evaluation and consumption process when potential consumers accept the legitimacy of shared information (i.e., quality of CGC) (Strack, 1999). As such, it is necessary to examine CGC in further detail, with specific emphasis placed on understanding how potential consumers process and evaluate the importance of different content.

\subsection{Types of CGC}

CGC is typically examined within the broader framework of user-generated content (UGC) (Gretzel \& Yoo, 2008). As such, extant classifications investigating the scope of UGC and electronic Word-of-Mouth (eWoM) (Table 1) do not take the type of CGC into sufficient consideration. Therefore, in order to develop and validate a scale centered on understanding the importance consumers place on social media sharing, it is first vital to examine CGC from different perspectives by acknowledging its various sub-dimensions.

Extant literature on UGC and CGC has established the importance of focusing on why consumers opt to share content online (Chung, Han \& Koo, 2015). Besides the basic provision of product, service, or experience-related information, individuals also generate content in order to satisfy hedonic needs (e.g., self-realization or gaining social status) (Lee \& Ma, 2012). As such, different personal motivations for sharing CGC often result in different types of content (Bulut \& Doğan, 2017). Further, potential consumers encountering content generated by existing consumers across social media platforms may allow this CGC to 
influence their own consumption behaviors (Litvin, Goldsmith \& Pan, 2008). In other words, 199 potential consumers may alter their behavior by attaching importance to content generated by 200 others. This is typically manifest in two ways: through utilitarian and hedonic appeal (Kotler \& Keller, 2012), as CGC pertaining to products, services or experiences is often underpinned by greater detail on functionality and effectiveness, with clear positive or negative connotations attached. Given the scale of contemporary user-led information sharing, extant research classifies CGC manifest online or via social media in multiple ways (Table 1). However, while demonstrating the practical and academic importance of the phenomena, the lack of consensus regarding the exact characteristics of CGC renders current classifications insufficient.

Table 1. Types of consumer-generated content (CGC)

\begin{tabular}{|c|c|c|}
\hline Author/s & Types & $\begin{array}{r}\text { Definitions } \\
\end{array}$ \\
\hline \multirow{4}{*}{$\begin{array}{l}\text { Kiecker } \\
\text { and Cowles } \\
\text { (2002, } \\
\text { p.79) }\end{array}$} & Spontaneous & $\begin{array}{l}\text { "Initiated and/or carried out by individual consumers using their own } \\
\text { means and know-how (e.g., via a personal email account or } \\
\text { homepage)." }\end{array}$ \\
\hline & Quasi-spontaneous & $\begin{array}{l}\text { "Initiated and/or carried out by individual consumers in web } \\
\text { environments created by marketers (e.g., corporate websites)." }\end{array}$ \\
\hline & $\begin{array}{l}\text { Independent or third } \\
\text { party-sponsored }\end{array}$ & $\begin{array}{l}\text { "Initiated and/or carried out by individual consumers in web } \\
\text { environments created by special interest groups, Professional } \\
\text { associations, and/or organizations for purposes other than selling } \\
\text { products." }\end{array}$ \\
\hline & Corporate-sponsored & $\begin{array}{l}\text { "Initiated by marketers, but carried out by individual consumers who } \\
\text { are paid and/or otherwise motivated to "spread the word" about a } \\
\text { product or company for the purposes of selling its products or } \\
\text { promoting the company." }\end{array}$ \\
\hline \multirow{2}{*}{$\begin{array}{l}\text { Park and } \\
\text { Lee }(2008, \\
\text { p.388) }\end{array}$} & Attribute-value & $\begin{array}{l}\text { "Attribute-value reviews are rational, objective and concrete based on } \\
\text { the specific facts about a product." }\end{array}$ \\
\hline & Simple-recommendation & $\begin{array}{l}\text { "Simple-recommendation reviews are emotional, subjective, and } \\
\text { abstract based on consumer feelings about a product." }\end{array}$ \\
\hline \multirow[t]{3}{*}{$\begin{array}{l}\text { Shao } \\
(2009, \text { p.9) }\end{array}$} & Consuming & $\begin{array}{l}\text { "Consuming refers to the individuals who only watch, read, or view but } \\
\text { never participate." }\end{array}$ \\
\hline & Participating & $\begin{array}{l}\text { "Participating includes both user-to-user interaction and user-to-content } \\
\text { interaction (such as ranking the content, adding to playlists, sharing } \\
\text { with others, posting comments, etc.). It does not include one's actual } \\
\text { production." }\end{array}$ \\
\hline & Producing & $\begin{array}{l}\text { "Producing encompasses creation and publication of one's personal } \\
\text { content, such as text, images, audio, and video." }\end{array}$ \\
\hline \multirow[t]{3}{*}{$\begin{array}{l}\text { Chu and } \\
\text { Kim (2011) }\end{array}$} & Opinion seeking & $\begin{array}{l}\text { Where an individual pursues information and recommendations from } \\
\text { others. }\end{array}$ \\
\hline & Opinion giving & $\begin{array}{l}\text { Where an individual provides information to others and influences them } \\
\text { through this information. }\end{array}$ \\
\hline & Opinion passing & $\begin{array}{l}\text { Where an individual conveys opinions to others through multi- } \\
\text { directional communication. }\end{array}$ \\
\hline \multirow[t]{2}{*}{$\begin{array}{l}\text { Ebermann } \\
\text { et al. } \\
(2011, \text { p.5) }\end{array}$} & Explicit & $\begin{array}{l}\text { "Explicit recommendations are intentionally provided from one SNS } \\
\text { user to another SNS user. Such recommendations may in particular be } \\
\text { given through direct communication channels such as Webmail-like } \\
\text { messaging within SNSs or as direct response to recommendation } \\
\text { requests in status messages." (i.e., explicit behavior refers to deliberate } \\
\text { recommendations). }\end{array}$ \\
\hline & Implicit & $\begin{array}{l}\text { "Even though the major goal of the information in users' profiles is not } \\
\text { to recommend something, it might have a recommendation effect on } \\
\text { users reading it because it refers to the products and services users } \\
\text { like." "Profile information that is not directed at specific other users in } \\
\text { form of direct user-to-user communication and might have a potential, } \\
\text { unintended recommendation effect is considered as implicit }\end{array}$ \\
\hline
\end{tabular}




\begin{tabular}{|c|c|c|}
\hline & & $\begin{array}{l}\begin{array}{l}\text { recommendation.” } \\
\text { recommendations). }\end{array} \\
\text { (i.e., implicit behavior refers to unintended }\end{array}$ \\
\hline \multirow[t]{2}{*}{$\begin{array}{l}\text { Yan et al. } \\
(2011, p .2)\end{array}$} & Score rating review & $\begin{array}{l}\text { "Score rating reviews give general comments about several aspects of } \\
\text { the purchasing process such as product quality, service logistics, and } \\
\text { service quality." }\end{array}$ \\
\hline & $\begin{array}{l}\text { Text-based online } \\
\text { review }\end{array}$ & $\begin{array}{l}\text { "Text-based online reviews usually give several comments about the } \\
\text { products or the buying experience." }\end{array}$ \\
\hline \multirow{2}{*}{$\begin{array}{l}\text { Zhang and } \\
\text { Lee (2012, } \\
\text { p.118) }\end{array}$} & Positive eWoM: & $\begin{array}{l}\text { "refers to consumers' description of pleasant experiences with a } \\
\text { product or their endorsement for a new product" }\end{array}$ \\
\hline & Negative eWoM & $\begin{array}{l}\text { "propagates rumors and scandals about a company or product, and } \\
\text { consumers' unpleasant experience with a product or company" }\end{array}$ \\
\hline \multirow{2}{*}{$\begin{array}{l}\text { Abrantes et } \\
\text { al. (2013, } \\
\text { p.1068) }\end{array}$} & In-group & “eWoM with close friends or family” \\
\hline & Out-of-group & $\begin{array}{l}\text { “eWoM with individuals beyond a person’s social, familial and } \\
\text { collegial circles” }\end{array}$ \\
\hline \multirow{2}{*}{$\begin{array}{l}\text { Kulmala et } \\
\text { al. (2013, } \\
\text { p.21) }\end{array}$} & Organic & $\begin{array}{l}\text { "Organic eWoM occurs naturally when a person wants to tell others } \\
\text { about a positive or negative experience with a product or a company" }\end{array}$ \\
\hline & Amplified & $\begin{array}{l}\text { "Amplified eWoM occurs when a marketer launches a campaign or in } \\
\text { some other way encourages others to speak about a product or a } \\
\text { company" }\end{array}$ \\
\hline \multirow{3}{*}{$\begin{array}{l}\text { Chen et al. } \\
(2013 \text {, } \\
\text { p.2080) }\end{array}$} & Evaluative & "The evaluation from the consumers after the use of Products" \\
\hline & Informative & $\begin{array}{l}\text { "Information that is stated clearly and logically, which allows users to } \\
\text { be attracted after receiving the message" }\end{array}$ \\
\hline & Benefit & $\begin{array}{l}\text { "A message that will cause direct or indirect conflict to consumer's } \\
\text { benefit" }\end{array}$ \\
\hline \multirow[t]{4}{*}{$\begin{array}{l}\text { O’Hern } \\
\text { and Kahle } \\
(2013 \text {, } \\
\text { p.23-26) }\end{array}$} & Informing & $\begin{array}{l}\text { "A process that engages users in the creation of content that either } \\
\text { praises or criticizes a particular product or brand (promotion-focused } \\
\text { user activity) and directs these user-generated reactions primarily at the } \\
\text { users' fellow customers (C2C knowledge flows)." }\end{array}$ \\
\hline & Pioneering & $\begin{array}{l}\text { "A process in which customers create their own new product } \\
\text { improvements (innovation-focused activity) and share these inventions } \\
\text { directly with their fellow users (C2C knowledge flow)." }\end{array}$ \\
\hline & Co-communicating & $\begin{array}{l}\text { "A process that occurs when users create their own novel marketing } \\
\text { materials (promotion-focused user activity) and share them directly } \\
\text { with a firm (C2B knowledge flow) to enhance the firm's marketing } \\
\text { communications." }\end{array}$ \\
\hline & Co-creating & $\begin{array}{l}\text { "A process that occurs when users create their own novel product } \\
\text { designs (innovation-focused user activity) and share these designs } \\
\text { directly with a firm (C2B knowledge flow) for the purpose of } \\
\text { enhancing the firm's new product offerings." }\end{array}$ \\
\hline \multirow{2}{*}{$\begin{array}{l}\text { Sparks et } \\
\text { al. (2013) }\end{array}$} & Specific content & Reviews about products are described clearly. \\
\hline & Vague content & Details contained in product reviews are much less specific. \\
\hline \multirow{3}{*}{$\begin{array}{l}\text { Weisfeld- } \\
\text { Spolter et } \\
\text { al. }(2014 \text {, } \\
\text { p.262) }\end{array}$} & Many-to-one & $\begin{array}{l}\text { "Many-to-one eWoM (e.g. the number of votes) represents the trend or } \\
\text { explicit preference of a crowd" }\end{array}$ \\
\hline & One-to-many & $\begin{array}{l}\text { "One-to-many text-based eWoM (e.g. product reviews) is descriptive } \\
\text { and requires the audience to use more cognitive effort to read the } \\
\text { reviews." }\end{array}$ \\
\hline & Many-to-many & $\begin{array}{l}\text { "Many-to-many eWoM (e.g. online discussion groups) is a high } \\
\text { involvement activity in which consumers continuously participate in } \\
\text { the communication process." }\end{array}$ \\
\hline \multirow{2}{*}{$\begin{array}{l}\text { Oh et al. } \\
(2015, \\
\text { p.138) }\end{array}$} & Internal eWOM & "internal eWoM provided by retailers” \\
\hline & External eWOM & “external eWoM provided by third-party informediaries or customers” \\
\hline \multirow{2}{*}{$\begin{array}{l}\text { Kim and } \\
\text { Johnson } \\
(2016)\end{array}$} & Informational eWoM & $\begin{array}{l}\text { Includes descriptions about functions, values, and benefits of brands } \\
\text { and products. }\end{array}$ \\
\hline & Emotional eWoM & $\begin{array}{l}\text { Refers to the atmosphere, emotions and feelings associated with brands } \\
\text { and products. }\end{array}$ \\
\hline $\begin{array}{l}\text { Fu et al. } \\
(2017,\end{array}$ & Commercial message & $\begin{array}{l}\text { "Promotion news, new products information, corporate social } \\
\text { responsibilities, fashion news related to brand" }\end{array}$ \\
\hline
\end{tabular}




\begin{tabular}{lll} 
p.27) Lifestyle affairs & $\begin{array}{l}\text { "Practical wisdom, meaningful articles, interesting videos or photos, } \\
\text { popular music or movies" }\end{array}$ \\
\cline { 2 - 3 } & $\begin{array}{l}\text { "Low service quality store, pleasant shopping experience, experience of } \\
\text { buying low quality product, news or articles with critical opinions" }\end{array}$ \\
\hline
\end{tabular}

Various gaps exist in prior studies examining the type and nature of CGC. Extant classifications (Table 1) demonstrate the lack of focus on the interaction between "where" and "with what motive" CGC is generated. For instance, Kiecker and Cowles (2002) emphasize that consumers can generate shared content on both their personal social media accounts and on those controlled by organizations, with their classification therefore focusing on "where" content is shared, not why. Nonetheless, Kiecker and Cowles (2002) do contend that consumers generate content in four ways (spontaneously, quasi-spontaneously, independently, or corporate-sponsored). The conceit of this classification is that the platforms where each type of content is generated are different. Spontaneous content, focused on individuals expressing their opinions through personal platforms (e.g., via email) ranks first in the authors' classification. Quasi-spontaneous content represents content generated by consumers on organizations' platforms. Third party-sponsored (independent) content focuses on mediator platforms that enable the flow of information between consumers, with no explicit objective of selling a product. Their fourth category, corporate-sponsored, covers content generated by organizations but spread by consumers, with either implicit or explicit recognition of the sponsored nature of this content.

However, this classification underplays the emotional motives that can underpin CGC. More specifically, consumers may not share opinions on products, services, or experiences with the sole purpose of informing others. As emphasized in social influence theories, a desire to 'be liked' or to receive social recognition could instead stimulate CGC. Accordingly, similar actions are likely to emerge from those who see, read, or hear CGC. Nonetheless, the possibility of fake content generated by fake consumers cannot be ignored (Burgess et al., 2011). In essence, this represents content shared by what appears to be consumers, but with hidden firm involvement or curation. Therefore, when classifying CGC, one should take into consideration platform differences and possible motive differences.

To this end, Shao (2009) contends that consumers demonstrate behavior in three ways. However, they play a key role in generating and developing content in only two of these three behaviors. Shao (2009) further states that individuals who exhibit 'participating behavior' share, rank, or comment on existing content only, whereas those demonstrating 'producing behavior' generate new content. However, this classification again provides scant detail regarding the information itself, the emotional appeal of the content, or the platforms where content is generated. Park and Lee (2008) focused directly on consumer product reviews. However, as mentioned prior, reviewing products is not the sole goal of social media sharing. CGC also encapsulates consumers' desire to demonstrate participation in experiences in more general terms. In such instances, while consumers are not reviewing products, services, or experiences, the content that they share could still encourage other potential consumers to engage with associated organisations and brands. Further, Chu and Kim (2011) examined eWoM on social networks, classifying it as: opinion seeking, opinion giving, and opinion passing. However, they did not suggest which type of content is more likely to be generated via individuals' own social media accounts compared to those aligned with organizations, despite the assertion that potential consumers perceive CGC with no organizational influence or involvement as more accurate and impartial (Bore et al., 2017).

Interestingly, Ebermann et al. (2011) suggest that individuals make recommendations either intentionally or without knowing that they are doing so, but do not differentiate the platforms where this distinction is manifest. Kulmala et al. (2013) consider eWoM either 
organic or amplified. The former resembles explicit personal recommendations (Ebermann et al., 2011), whereas the latter echoes corporate-sponsored content (Kiecker \& Cowles, 2002). underpinned by clear organizational involvement on social networks, with content generated by consumers on their own social media profiles ignored. Finally, Wu and Wang (2011), Kim and Johnson (2016), and Liu et al. (2017) examined eWoM in the rational and emotional context. However, they again did not discuss the platforms upon which this occurred or how eWoM surfaces.

As such, shortcomings remain across extant research necessitating a more robust classification of CGC. This principally emerges from the lack of insight into the interaction between the platform used for sharing and the potential motive behind CGC. Research can assess these two elements separately. However, developing a classification based on the interaction between both is likely to yield results that are more valuable. Specifically, it may be beneficial to classify CGC based on where the sharing takes place and what the motive behind shared CGC is, allowing scholars and practitioners to examine CGC from a different perspective.

This study recognizes that consumers can generate content in their own social media accounts or on profiles, accounts, and pages that relevant organizations administer. This may lead potential consumers to attach different levels of importance to such content. Potential consumers might therefore pursue reliable information and social value through the content shared by others. Information seeking is generally carried out with utilitarian purposes, especially in the tourism industry where consumers use CGC to gain detailed user reviews of destinations, travel agencies, hotels, experiences, or excursions (Hays, Page \& Buhalis, 2013). However, as individuals often derive pleasure from content they encounter, the relevance of the information shared should also be examined in terms of hedonic impact (Chen et al., 2015). For example, tourism scholars often attach emotional value to the process of information searching and travel planning (Sigala, 2018). Interesting CGC can prompt potential consumers to pursue the same experience as others (Chen et al., 2015); if CGC demonstrates experiences that potential consumers consider particularly enjoyable or aspirational, this may trigger their desire to experience the same thing. To this end, Sedera et al. (2017) suggest that individuals attribute different levels of importance to different types of content, and that CGC with a high level of social influence is particularly powerful in encouraging potential consumers to follow suit.

This supports the central tenets of social learning (SLT) and social identity theories (SIT). According to SLT, behavior is learned from the environment through observation. Individuals often demonstrate the same behaviors as others in order to obtain desirable outcomes (Bandura, 1977). Considering SLT from the perspective of consumer behavior, one can expect that the attitudes and behaviors of consumers are formed and enhanced by their friends. More clearly, when individuals observe desirable consequences stemming from the actions taken by friends and family, they are likely to adopt similar behaviors (Webb \& Zimmer-Gembeck, 2014). Similarly, self-esteem underpins SIT. Individuals' self-esteem may develop due to exhibiting behaviors accepted by society. If individuals feel accepted by those that they respect, their self-esteem may increase (Stets \& Burke, 2000). Here, CGC can enhance an individuals' self-esteem if they attach importance to the information shared (Valkenburg et al., 2006).

Further, social comparison and social contagion theories can explain potential consumers' desire to undertake similar experiences demonstrated via CGC (Ozimek, Bierhoff, \& Hanke, 2018). According to social comparison theory, individuals compare themselves with other individuals or groups. When considered aspirational, such individuals can have similar ideas and stimulate similar attitudes and behaviors via upward social comparison (Lee 
\& Watkins, 2016). Some individuals exhibit similar attitudes and behaviors (and pursue similar experiences) to others in order to avoid social disapproval (Cox \& Bauer, 1964) or to achieve social approval (Jellison \& Gentry, 1978). Further, according to social contagion theory, individuals mirror the beliefs, attitudes, and behaviors of others who they care about

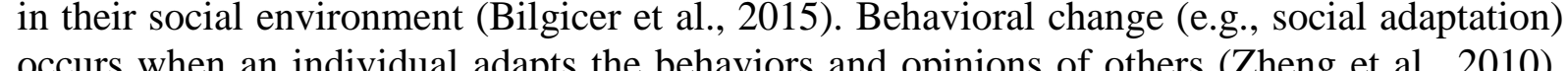
This change is mediated by communication between actors (Scherer \& Cho, 2003), with CGC serving as an increasingly prevalent example of this. Here, tourists encountering CGC pertaining to destinations, experiences, or activities that they deem aspirational, exciting, and impartial may place greater importance upon it, and subsequently exhibit similar behaviors. Finally, there may be a desire for recognition from others who have liked the shared content, or from those who hope to experience the same activity under the influence of uniformity behaviors that emerge due to group pressure (Tajfel \& Turner, 1979).

In brief, potential consumers attribute importance to social media sharing in two key ways, contingent on whether it offers the opportunity to: (1) obtain reliable information and (2) gain prestige, social status, and/or recognition. Therefore, the importance individuals attach to shared content differs in line with type of content shared.

\subsection{CGC as participant and non-participant sharing}

While CGC can focus on presenting oneself to others, finding out about or planning events, browsing or posting media, and generally seeking or sharing information (Malik, Dhir, \& Nieminen, 2016), it can be categorized based on its emotional, hedonic, and functional appeal (Table 1). However, beyond this reductive differentiation it is also important to consider how individuals generate content across platforms. Therefore, it is necessary to generate a classification that takes into account CGC on consumers' own social media accounts/profiles and on platforms with direct or indirect organizational involvement.

To this end, consumers typically generate social media content in either a (i) participatory or (ii) non-participatory manner. Participant content sharing refers to when individuals post on social media accounts associated with organizations or brands, or when they share content with a specific purpose directly related to an organization (e.g., providing product information and evaluation) (Dedeoğlu, 2016). Under such circumstances, the functional information that consumers share may benefit organizations by providing direct or indirect feedback, which can subsequently be used to improve products and services (Eley \& Tilley, 2009). Stemming from notions of participant behavior established in consumer behavior literature, consumers might share positive information regarding high quality products and services that meet their expectations, whereas they may also contribute to product and service improvement by sharing negative information, constructive feedback, or critical reviews of products and services that did not meet their expectations (Eley \& Tilley, 2009). As such, participative CGC can hold a positive or negative sentiment, and can include co-creation, co-destruction, and brand agitation behaviors (Dolan et al., 2016; Hewer, Gannon \& Cordina, 2017). Crucially, as this content is shared on social media accounts with direct or indirect organizational involvement, CGC represents a participative interaction between consumer and firm. Thus, while consumers may hold different motives for generating participative content, it mainly plays a utilitarian role (Kamboj \& Sarmah, 2018); characterized by information sharing, experience transfer, and information seeking (Chae \& Ko, 2016).

However, not all CGC emerges on platforms with organizational involvement and/or control (Tajvidi et al., 2017). Consumers can generate and share content on their own or their 
friends' social media channels (e.g., blogs and social network profiles) without participating in any activity directly related to a brand or seeking any recognition from an organization (Dedeoğlu, 2016). This non-participant sharing therefore typically refers to shared content posted by an individual driven by social or hedonic motives (e.g., a desire to be liked, socialization, or self-expression). Under such circumstances, consumers do not prioritize product and/or service improvement, and this CGC does not typically serve a functional purpose (Alsufyan \& Aloud, 2017). As such, individuals posting content in their own or their friends' social media profiles, or generating content on private blogs, are primarily regarded as engaging in non-participant sharing behavior. This CGC is therefore generated with the motive of sharing experiences and opinions with friends and family, rather than simply sharing information for the benefit of others or directly interacting with organisations and brands. By generating content spontaneously in their own and their friends' social media accounts, consumers can provide them with information relating to goods and services without participating in the product or service development process (Kamboj \& Sarmah, 2018).

As such, CGC classified as non-participant sharing is typically born from different motives, including: making new friends, staying in touch with friends, relaxation, passing time, a desire to be liked, enjoyment, improving self-image, and prestige-seeking - satisfying consumers' social and hedonic desires in the process (Shao \& Kwon, 2019). To this end, within the context of non-participant sharing and hedonic motivations, Heinonen (2011) identified two core categories: 'social connection' and 'entertainment'. Regarding social connection, consumers generate and share content in order to show new things to their social circle, to feel a sense of belonging to their social circle, to follow up on events and friends' activities, to stay connected with their social circle, and to expand upon existing relationships. In doing so, CGC may serve as a form of self-expression, helping consumers to manage and curate their self-image - emphasizing the hedonic motives of non-participant sharing. As such, non-participant sharing typically holds greater emotional value than the more functional participant sharing behaviors (Krishnamurthy \& Dou, 2008).

\subsection{CGC as a driver of brand awareness}

Extensive and well-positioned CGC can significantly increase consumers' awareness of organizations and brands (Sigala, 2018). Brand awareness represents the "strength of the brand node or trace in memory, as reflected by consumers' ability to identify the brand under different conditions” (Keller, 1993, p. 3). Foroudi (2019) suggests that brand awareness is comprised of two core elements: brand recall and brand recognition. Brand recall refers to the "consumer's ability to recall a brand when given the product category", whereas brand recognition represents "consumers' ability to confirm prior exposure to the brand when given the brand as a cue" (Keller, 1993, p.3). As such, the ability of CGC to attract widespread attention while also providing brand-related information can serve to increase potential consumers' knowledge and awareness of brands and organizations. In other words, organizations can become more familiar with potential consumers by understanding, analysing, and encouraging shared content created by existing consumers. According to the associative network model, memory consists of nodes, defined as stored information connected by links that vary in strength (Keller, 2013). Within the context of tourism, a destination brand serves as a possible node (Pike et al., 2010). Brand awareness reflects the strength of the brand node in the consumer mind (Kladou \& Kehagias, 2014), with destination brand awareness defined as the tourist's ability to recall and recognize a destination (Gómez, Lopez, \& Molina, 2015). Thus, destination brand awareness can play a vital role in the 
decision-making process, as it encapsulates the presence and strength of the destination image in the minds of potential tourists (Gannon et al., 2017).

The content created by others is often considered more influential than FGC because it is considered more genuine and reliable (Herrero et al., 2015). The fact that potential consumers consider the content created by existing consumers as important may increase their level of involvement and likelihood of sharing in future (Arndt, 1967). This increased involvement echoes SLT, which examines how human behaviors can be explained in terms of continuous reciprocal interaction among cognitive, behavioral, and environmental factors. These behaviors are learned through observation, where individuals mimic the behavior of others to obtain desired outcomes (Bandura, 1977). From a consumer behavior perspective, SLT suggests that the activities carried out by close friends form and strengthen consumers' behaviors (Webb \& Zimmer-Gembeck, 2014). Thus, potential consumers may increase their level of involvement with the subject of the shared content, with involvement defined as a motivational situation that generally affects consumer decision-making (Cohen, 1983). This increase in the level of involvement can lead potential consumers to search for more information (Gursoy \& Gavcar, 2003). In this context, CGC (both participant sharing and non-participant sharing) act as stimuli and increase involvement with content. This allows individuals to search for information relating to the phenomenon being shared. To this end, potential customers' level of awareness of products, services, experiences, and destinations are likely to be positively influenced. Therefore:

$\boldsymbol{H}_{1}$ : The importance attached to participant sharing in social media (IPS) influences destination brand awareness in a positive and significant way.

$\boldsymbol{H}_{2}$ : The importance attached to non-participant sharing in social media (INPS) influences destination brand awareness in a positive and significant way.

Testing these hypotheses is crucial to approving the application of the proposed ISMS scale, as it is vital to recognize whether it has predictive validity. In order to do so, the relationship between the newly developed scale and brand awareness was tested (DeVellis, 2003).

\section{Methods and Scale Development}

In order to conduct extensive and robust scale development, the stages recommended by Churchill (1979) were followed. Given the context of this study, attention was paid to the processes used in various scale development projects undertaken across extant hospitality and tourism research (e.g., Kim et al., 2015; Pan et al., 2017; Taheri, Gannon, Cordina \& Lochrie, 2018). As such, the scale development process consists of four distinct phases (Figure 1): Phase 1 deals with item generation and the formation of constructs. In Phase 2, item "purification" was conducted. In Phase 3, the initial validation and application of the ISMS scale was performed. In Phase 4, the ISMS scale was replicated in a different context. 
Based on the literature review, 37 statements were created.

$>$ Using ethnographic research, over 100 social media users were observed.

$>$ Eight (mixed female and male) marketing doctoral students were interviewed.

$>$ Ten social media users were interviewed.

$>$ Nine experts in social media reviewed the items again.

$>3$ specialist academics ( 2 professors and 1 assistant professor) working in the field of tourism were consulted to ensure face validity.

$>$ Following these steps, 11 expressions were used for the pre-test.

\section{(1)}

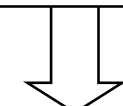

\begin{tabular}{|l|}
\multicolumn{1}{|c|}{ Phase 2-Initial item purification (Study 1) } \\
\hline A pilot test was conducted on 78 tourists. \\
Exploratory factor analysis was applied with principal component. \\
Communalities \\
Reliability analysis
\end{tabular}

\section{2}

473

555 participants

Assignment of missing values; examining the outliers

> Controlling the normal distribution assumption

$>$ EFA was applied with principal component

$>$ Reliability analysis

> Confirmatory factor analysis (CFA) was applied with maximum likelihood

$>$ Examining validity of reliability of constructs (composite reliability, convergent validity and discriminant validity)

$>$ Controlling common method bias

$>$ Examining the nomological and predictive validity

Examining cross-validation of scale (configural, metric and scaler invariance)

Comparison of scale constructs

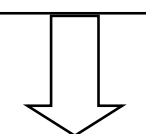

\begin{tabular}{|l|}
\hline \multicolumn{1}{|c|}{ Phase 4-Replication in another country (Study 3) } \\
\hline 630 participants \\
$>$ Assignment of missing values; examining the outliers \\
$>$ Controlling the normal distribution assumption \\
$>$ CFA was applied with maximum likelihood \\
$>$ Examining validity of reliability of constructs (composite reliability, convergent validity and discriminant validity) \\
$>$ Controlling common method bias \\
$>$ Examining the nomological and predictive validity
\end{tabular}




\subsection{Item generation and construct formation (Phase 1)}

482

483

484

485

486

487

488

489

490

491

492

493

494

495

496

497

498

499

500

501

502

503

504

505

506

507

508

509

510

511

512

513

514

515

516

517

518

519

520

521

522

523

524

525

526

527

528

529

530
This study generated an initial item pool in two stages: First, an extensive literature review was conducted in order to identify relevant ISMS items and sub-dimensions within the context of tourism. As no similar scales exist across extant discourse, items could not be taken wholesale from established sources. Therefore, the second stage of the initial item pool development involved undertaking ethnographic research. By conducting participant observation, this information was classified as either "non-participation" or "passive participation” (DeWalt \& DeWalt, 2011). Wen et al. (2018) support the use of ethnographic research methods in both social and consumption-centric situations. For this study, the first author observed the conduct of over 100 social media users across popular platforms (e.g., Instagram and Facebook). More specifically, (1) content created by consumers on the social media profiles of various tourism organizations, and (2) content created by consumers in their own and their friends' social media profiles were examined. In order to explore whether the statements generated accurately captured the ISMS construct, a mixed cohort of marketing doctoral students were interviewed. These semi-structured interviews started with broad questions, such as 'Why did this social media user generate this content?' or 'What is your opinion on why this social media user generated this content?' These questions led to in-depth conversations about the social media interaction and purpose of the content (Taheri et al., 2018). The first author then consulted and shared their notes and findings with the other members of the research team. Subsequently, an initial pool of 37 items was generated.

Next, the research team sought the judgment of individuals with expertise in both tourism and social media marketing, alongside a number of individuals who, while not considered experts in the field, used social media extensively. These views were collected in order to assess the "readability" of the 37 items generated via short conversation-style interviews were conducted. While selecting the non-expert participants, we endeavored to select those who used social media for general purposes $(n=5)$ and those who engaged with tourism-related content $(n=5)$. Half of these participants were female, with ages ranging from 22-53. These ten individuals were asked to review the 37 items concerning clarity, necessity, and similarity. Three participants from the group using social media for general purposes identified five 'unclear and complicated' expressions. Four people from the group focused on tourism-related sharing defined eight statements as unnecessary and overly similar. Therefore, 13 items were excluded at this stage because they were unclear, unnecessary, or held deficiencies. Next, nine scholars recognized as experts in the field reviewed the remaining 24 items. These experts were asked to read the definition of each dimension and place each item under a corresponding dimension. Items they considered meaningless were to be marked as "not applicable" and items the experts could not agree upon were subsequently eliminated. As a result, the panel of experts marked 11 items as non-relevant and the authors therefore excluded them from the study.

Finally, the authors consulted a further panel of experts to ensure face validity. At this stage, three scholars (two professors and one assistant professor, all within business faculties) with expertise in the tourism field were consulted on whether the statements were applicable and represented the associated dimensions. As two of the experts indicated that two items were "not applicable" in measuring their associated dimension, those items were removed from the scale. The scale therefore was finalized before the pre/pilot test (Table 2), and face validity was supported. 
Table 2. Measurement Items

\begin{tabular}{|c|c|c|}
\hline \multicolumn{2}{|c|}{ Dimensions } & Measurement Items \\
\hline \multirow{7}{*}{ IPS } & IPS1* & $\begin{array}{l}\text { When choosing a destination, recommendations of others on a destination website and/or on social } \\
\text { media websites (Facebook, Instagram, etc.) about the destination are important to me. }\end{array}$ \\
\hline & IPS2* & $\begin{array}{l}\text { When choosing a destination, sharing of others on a destination website and/or on social media } \\
\text { websites (Facebook, Instagram, etc.) about the destination are important to me. }\end{array}$ \\
\hline & $\overline{\text { IPS3 }}$ & $\begin{array}{l}\text { When choosing a destination, comments of others on a destination website and/or on social media } \\
\text { websites (Facebook, Instagram, etc.) about the destination are important to me. }\end{array}$ \\
\hline & IPS4 & $\begin{array}{l}\text { When choosing the destination, ratings of others on a destination website and/or on social media } \\
\text { websites (Facebook, Instagram, etc.) about the destination are significant to me. }\end{array}$ \\
\hline & IPS5 & $\begin{array}{l}\text { When choosing a destination, ratings of other users on websites (e.g., TripAdvisor, booking.com) } \\
\text { where travel evaluations are included and holiday packages are sold are important to me. }\end{array}$ \\
\hline & IPS6 & $\begin{array}{l}\text { When choosing a destination, comments of other users on websites (e.g., TripAdvisor, booking.com) } \\
\text { where travel evaluations are included and holiday packages are sold are important to me. }\end{array}$ \\
\hline & $\overline{\text { IPS7* }}$ & $\begin{array}{l}\text { When choosing a destination, recommendations of other users on websites (e.g., Trip advisor, } \\
\text { booking.com) where travel evaluations are included and holiday packages are sold are important to me. }\end{array}$ \\
\hline \multirow{4}{*}{ INPS } & INPS1 & $\begin{array}{l}\text { Holiday related comments of other users on their own social media accounts (profiles) (Facebook, } \\
\text { Twitter, blogs, etc.) are important to me. }\end{array}$ \\
\hline & INPS2 & $\begin{array}{l}\text { Holiday related sharing of other users on their own social media accounts (profiles) (Facebook, } \\
\text { Twitter, blogs, etc.) are important to me. }\end{array}$ \\
\hline & INPS3 & $\begin{array}{l}\text { Holiday recommendations of other users on their own social media accounts (profiles) (Facebook, } \\
\text { Twitter, blogs, etc.) are important to me. }\end{array}$ \\
\hline & INPS4 & $\begin{array}{l}\text { Holiday related sharing (photo, video) of other users on social media accounts of others (profiles) } \\
\text { (Facebook, Twitter, blogs, etc.) are important to me. }\end{array}$ \\
\hline
\end{tabular}

Notes: *Item deleted following exploratory factor analysis; IPS: Importance attached to participant sharing; INPS: Importance attached to non-participant sharing.

\section{Initial item purification (Phase 2)}

The initial item reduction was conducted using data collected from tourists in one of Turkey's most popular travel destinations - Alanya. The questionnaire was prepared in Turkish and translated into different languages (English, German, and Russian) in order to allow the research team to collect data from a wide spread of tourists. The back-translation method ensured this translation was conducted robustly (Gannon et al., 2017). In practice, this meant that the questionnaire was prepared in Turkish and translated into English. It was then edited by native English-speaking academics. This copy was sent to translators with knowledge of both the source (English) and target (German, Russian and Turkish) languages. After this stage, the language in each questionnaire (English, German, Russian and Turkish) was compared for inconsistencies. This comparative stage was crucial in ensuring consistency of meaning across languages.

As there were no differences in the translated scales, it was decided to use the scale edited after proofreading for the English questionnaires, and to use the translated scales, retranslated after the first translation phase, for the German, Russian, and Turkish ones. In order to eliminate possible mistakes, a pre-test was conducted on 10 individuals selected for each scale prepared in each of the four languages. Following this pre-test, it was clear that there were no communication, language, or understanding problems with the scale items, allowing the research team to proceed to the scale refinement and validity stages.

In order to verify the psychometric features of the new measurement scale, an initial reduction stage test was conducted (Hinkin et al., 1997) with 78 tourists in Alanya. This is satisfactory according to Johnson and Brooks (2010). These tourists were selected on a voluntary basis via convenience sampling. A seven-point scale ranging from "strongly disagree" (1) to "strongly agree" (7), with no distinct labels for scale points $2-6$, accompanied each item. To identify the underlying structure of the importance attached to social media sharing (ISMS), exploratory factor analysis (EFA) was used to analyze this data.

Around 55\% (43) of the pilot study participants were male, while $45 \%$ (35) were female. Among the participants, $24.3 \%$ (19) were aged 50 or over, and each of the following: 
18-25 (13), 26-33 (13), 34-41 (13) and 42-49 (13) age groups had a rate of 16.7\%. Only seven participants (8.97\%) were 17 or younger. Regarding marital status, 23 participants were married (29.5\%) while 55 were single (70.5\%). Concerning education, $12.8 \%$ of the participants (10) had completed post-graduate education, while 44.9\% (35) held a bachelor's degree. $80.8 \%$ (63) of participants were traveling with an agency and $24.4 \%$ stated that they were visiting Alanya for the first time. 30.8\% (24) of the participants did not have any children and 33.3\% (26) had one child. Finally, 30.8\% (24) of the participants stayed in fourstar hotel accommodation and $28.2 \%$ (22) stayed in five-star hotel accommodation.

572

\subsection{Initial validation and application of the ISMS Scale (Phase 3)}

574

575

To further verify the constructs identified in Phase 2, reliability and construct validation techniques were used to assess the scale items measuring the newly developed ISMS construct (Hair et al., 2014; Taheri, Jafari \& Okumus, 2017). A professional research company assisted the authors when administering the questionnaires. During the data collection process, four professional interviewers, trained on the nature of the study, were assigned by the research company. Questionnaires were administered in areas of relevance to tourists, such as beaches, souvenir shops, restaurants, and hotel lobbies in Alanya, Turkey. The authors conducted and distributed the questionnaires at various locations, collecting responses over 14 days. Respondents were again selected using convenience sampling.

This stage reached 800 participants. Hair et al.'s (2014) suggestion was taken into consideration in this screening process. Accordingly, questionnaires that were not filled in more than $15 \%$ and answered as "straight lining" were discounted from the analysis process. Overall, 245 questionnaires were excluded from the analysis as they contained missing values or were not adequately completed. In total, data obtained from 555 respondents was used. The methods and algorithms proposed by Westland (2012) were employed to determine whether the number of samples obtained in the current study could test the proposed model. Therefore, this study uses the a-priori sample size calculator for SEM (Soper, 2017). This requires input data such as the anticipated effect size, statistical power levels, and the number of observed variables and latent variables in the model, alongside the desired probability, to detect the minimum sample size for conducting SEM. The results indicate that the minimum sample size should be 545 for a model with three latent variables; 16 observed variables; 15 low anticipated effect size; .80 desired statistic power level; and .05 probability level. Therefore, our sample $(\mathrm{n}=555)$ surpassed the recommended minimum.

Further, missing value and outlier assignments were used (Hair et al., 2014). The assumption of normal distribution was also checked. Missing values were specified with the mean substitution method, and Mahalanobis distance was examined to determine outliers. One outlier was determined and removed (Mahalanobis D (16) $>57.794, p<.001$ ) (Hair et al., 2013), leaving 554 cases for data analysis. Finally, a normal distribution assumption was checked, as the maximum likelihood method was used in estimating the measurement model. Skewness values were between -.580/.073 and kurtosis values were between -1.103/.062; thus, the data had normal distribution (Kline, 2011) (Table 3).

605 
Table 3. Descriptive statistics (Phase $3 \&$ Phase 4)

\begin{tabular}{|c|c|c|c|c|c|c|c|c|}
\hline \multirow[t]{2}{*}{ Items } & \multicolumn{4}{|c|}{ Phase $3(n=554)$} & \multicolumn{4}{|c|}{ Phase $4(n=629)$} \\
\hline & Mean & SD & Skewness & Kurtosis & Mean & SD & Skewness & Kurtosis \\
\hline $\begin{array}{l}\text { When choosing a destination, comments of others on a destination website and/or on social media } \\
\text { websites (Facebook, Instagram, etc.) about the destination are important to me.(IPS3) }\end{array}$ & 4.33 & 1.26 & -.18 & -.52 & 4.31 & 1.27 & -.16 & -.61 \\
\hline $\begin{array}{l}\text { When choosing a destination, ratings of others on a destination website and/or on social media websites } \\
\text { (Facebook, Instagram, etc.) about the destination are significant to me.(IPS4) }\end{array}$ & 4.26 & 1.45 & -.34 & -.70 & 4.25 & 1.45 & -.31 & -.76 \\
\hline $\begin{array}{l}\text { When choosing a destination, ratings of other users on websites (e.g., TripAdvisor, booking.com) where } \\
\text { travel evaluations are included and holiday packages are sold are important to me.(IPS5) }\end{array}$ & 4.36 & 1.19 & -.13 & -.54 & 4.37 & 1.17 & -.15 & -.51 \\
\hline $\begin{array}{l}\text { When choosing a destination, comments of other users on websites (e.g., TripAdvisor, booking.com) } \\
\text { where travel evaluations are included and holiday packages are sold are important to me.(IPS6) }\end{array}$ & 4.41 & 1.34 & -.58 & -.12 & 4.40 & 1.33 & -.57 & -.15 \\
\hline $\begin{array}{l}\text { Holiday related comments of other users on their own social media accounts (profiles) (Facebook, } \\
\text { Twitter, blogs, etc.) are important to me.(IPNS1) }\end{array}$ & 4.33 & 1.20 & -.43 & -.01 & 4.37 & 1.18 & -.43 & -.07 \\
\hline $\begin{array}{l}\text { Holiday related sharing of other users on their own social media accounts (profiles) (Facebook, Twitter, } \\
\text { blogs, etc.) are important to me.(IPNS2) }\end{array}$ & 4.22 & 1.31 & -.51 & .06 & 4.21 & 1.31 & -.49 & .00 \\
\hline $\begin{array}{l}\text { Holiday recommendations of other users on their own social media accounts (profiles) (Facebook, } \\
\text { Twitter, blogs, etc.) are important to me.(IPNS3) }\end{array}$ & 4.38 & 1.20 & -.40 & -.18 & 4.40 & 1.20 & -.40 & -.28 \\
\hline $\begin{array}{l}\text { Holiday related sharing (photo, video) of other users on social media accounts of others (profiles) } \\
\text { (Facebook, Twitter, blogs, etc.) are important to me.(IPNS4) }\end{array}$ & 4.39 & 1.22 & -.40 & .02 & 4.43 & 1.18 & -.37 & -.06 \\
\hline I can imagine what...looks like.(Awareness) & 3.87 & 1.47 & -.05 & -1.10 & 3.85 & 1.44 & -.04 & -1.06 \\
\hline I am aware of....as a travel destination.(Awareness) & 3.89 & 1.60 & -.08 & -.84 & 3.87 & 1.51 & .00 & -.75 \\
\hline I can recognize....among other similar destinations.(Awareness) & 3.96 & 1.47 & .07 & -.95 & 3.92 & 1.45 & .11 & -.94 \\
\hline Some characteristics of...come to my mind quickly.(Awareness) & 4.00 & 1.43 & -.15 & -1.04 & 3.96 & 1,41 & -.12 & -1.06 \\
\hline I can quickly recall the marketing activities about...(Awareness) & 3.99 & 1.38 & -.03 & -.77 & 3.97 & 1.35 & .00 & -.77 \\
\hline
\end{tabular}


Of the 554 participants, $44.2 \%$ (245) were male, while $55.8 \%$ were female (309);

492

493

494

495

496

497

498

499

500

501

502

503

504

505

506

507

508

509

510

511

512

513

514

515

516

517

518

519

520

521

522

523

524

525

526

527

528

529

530

531

532

533

534

535

536

537

538

539 $66.8 \%$ (370) were aged 49 and below, 33.2\% (184) were 50 and above; 273 were married (49.3\%) and 281 were single (50.7\%). In terms of education, $7.4 \%$ (41) were post-graduate educated; 23.3\% (129) held bachelor's degrees; 28\% (155) had high school degrees; and 24.4\% (135) had an associate's degree. Overall, 78.7\% (436) traveled with an agency, and $35 \%$ (194) stated that they were visiting Alanya for the first time. Further, 18.8\% (104) had no children, 31.8\% (176) had one child, and 34.1\% (189) had two children; 34.7\% (192) were staying in four-star hotels and 23.8\% (132) were staying in five-star hotels.

Composite reliability was examined alongside convergent and discriminant validity. Then, common method bias (CMB), nomological validity and predictive validity were checked. CMB was controlled through Harman's Single-Factor Approach using confirmatory factor analysis (CFA) (Podsakoff, MacKenzie, Lee \& Podsakoff, 2003). In order to obtain information concerning the structure and validity of the scale, EFA was applied. Reliability levels of the structures obtained after construction were examined. CFA was subsequently applied to confirm the obtained structure, with construct validity examined. In order to investigate nomological and predictive validity, the structural equation modeling approach was used. Destination awareness was selected, as it was an expected antecedent of ISMS. In doing so, destination awareness was adopted from Ferns and Walls (2012) and measured via five items. Then, the cross-validation of the ISMS scale construct was checked through measurement invariance tests. Finally, in order to determine the correct construct for the ISMS scale, the one-factor model was compared under two groups: a two-factor first-order model and a two-factor second-order model (Appendix 1).

\subsection{Replication in another country (Phase 4)}

Hinkin et al. (1997, p.15) contend that it is "necessary to collect another set of data from an appropriate sample and repeat the scale-testing process with the new scales", and this "replication should include confirmatory factor analysis, assessment of internal consistency reliability and construct validation". Accordingly, the ISMS scale was replicated using data obtained from tourists in Glasgow, Scotland. Over 14 million tourists arrived in Scotland in 2015, with Glasgow welcoming $15 \%$ of them. Further, domestic tourists spent a total of £4.97billion, of which 12\% was spent in Glasgow (VisitScotland, 2016). As such, Glasgow is at the heart of Scotland's tourism sector, making it a suitable candidate for this replication phase. Indeed, while the Turkish tourism industry typically relies on those seeking the 3Ss (i.e., sun-sea-sand) (Alvarez, 2010), the Scottish tourism industry is underpinned by those seeking culture and heritage (VisitScotland, 2017). As a result, each context is sufficiently diverse and likely to host different types of tourists. The sample collected from Scotland for the purpose of replication is therefore crucial in checking whether the items in the newly developed ISMS scale were appropriate for different types of tourists in markedly different contexts.

The a-priori sample size calculator was again used to determine sample size. As per Phase 3, this indicated that the minimum sample size should be 545 . Overall, data was collected from 630 participants at this stage, indicating that the sample used for replication is sufficient. The data screening process was employed in line with the previous stage. The mean substitution method was first used to identify missing values. Second, Mahalanobis distance was examined to determine outliers in the study. Because one outlier was detected, this subject was excluded from the data (Mahalanobis’ D (13) $>49.285, p<.001$ ). Finally, the assumption of normal distribution was checked as the maximum likelihood method was used in estimating the measurement model. As skewness values were between -.579/.110 and kurtosis values were between $-1.063 / .001$, the distribution of the data was considered 
'normal' (Kline, 2011) (Table 3). Overall, data from 629 participants was used at the 541 replication stage of the analysis.

The demographic results indicate the following participant age distribution: 17 and

\section{Results}

\subsection{Initial Items' purification (Phase 2)}

Before discussing the EFA results, Kaiser-Meyer-Olkin (KMO), the measure of sample adequacy, and Bartlett's test of Sphericity were examined. The KMO value is very close to the limit (Tabachnick \& Fidell, 2012), while the correlations among the measurement items are sufficient according to the result of Bartlett's test of Sphericity (Hair et al., 2013). After examining the appropriateness of the data, EFA was performed using a principle component analysis and the varimax rotation method. Appendix 2 presents the correlation matrix for the initial item purification stage.

Communalities were examined. Only one item was found to be below the recommended value of .50 (Hair et al., 2013). However, this was disregarded because the value was very close to .50 and the scale in question was examined with an exploratory purpose. As a third step, factor loadings were examined. In light of the Eigenvalue, the factor construct gives clues about a four-dimensional construct; however, the factor loadings were not excluded from the scale since the minimum recommended value exceeded .50 (Hair et al., 2013) (Table 4). Therefore, the ISMS scale composed of 11 items was used for analyses to be carried out for validation and application.

Table 4. Results of the factor analysis and reliability test (Phase 2)

\begin{tabular}{|c|c|c|c|c|c|c|}
\hline Dimension & $\begin{array}{c}\text { Factor } \\
\text { Loadings }\end{array}$ & Eigenvalue & $\begin{array}{c}\% \text { of } \\
\text { Variance* }\end{array}$ & $\begin{array}{c}\text { Cronbach's } \\
\alpha\end{array}$ & KMO & $\begin{array}{l}\text { Bartlett's } \\
\text { test of } \\
\text { sphericity }\end{array}$ \\
\hline First & $\begin{array}{l}.943 \\
.934 \\
.918\end{array}$ & 3.27 & 26.58 & .936 & \multirow{4}{*}{.62} & \multirow{4}{*}{$\begin{array}{c}p<.001 \\
\text { Approx. } \\
\text { Chi- } \\
\text { square= } \\
464,273 \\
\text { df=55 }\end{array}$} \\
\hline Second & $\begin{array}{l}.802 \\
.834 \\
.788 \\
.794 \\
\end{array}$ & 2.45 & 23.70 & .820 & & \\
\hline Third & $\begin{array}{l}.761 \\
.941\end{array}$ & 1.60 & 15.50 & .751 & & \\
\hline Fourth & $\begin{array}{l}-.490 \\
.854\end{array}$ & 1.01 & 10.12 & -.094 & & \\
\hline
\end{tabular}




\subsubsection{Exploratory research - Phase 3}

In this phase, EFA was again applied. Kaiser-Meyer-Olkin (KMO) and Bartlett's test of Sphericity were also examined in order to check the applicability of EFA. The KMO value (.82) and a significant chi-square value for the Bartlett's test of Sphericity $\left(\chi^{2}=2704.09, \mathrm{df}=55\right.$, $p<.001)$ indicated that factor analysis was appropriate for the data collected. The EFA shows three factors with Eigenvalues $\geq 1$ and explains $66.56 \%$ of the variance in the data. It explains $28.5 \%$ of the first factor variance, $28.2 \%$ of the second factor variance, and $9.7 \%$ of the third factor variance. However, some items had low commonalities $(<.50)$. Therefore, an iterative process eliminated items that had commonalities below .50 (Hair et al., 2013). According to the results of repeated factor analysis, the KMO value of .83 and a significant chi-square value for the Bartlett's test of Sphericity $\left(\chi^{2}=2536.22, \mathrm{df}=28, p<.001\right)$ indicated that factor analysis was appropriate for the data. The final factor analysis also resulted in two factors with Eigenvalues $\geq 1$ and explained $75.23 \%$ of the total variance. The first factor, INPS, included four items and explained $<37.97 \%$ of the variance. The second factor, IPS, contained four items and captured nearly $37.26 \%$ of the variance. Cronbach's alpha values were checked for internal consistency, with all dimensions $>.70$ ( $\alpha=.88$ for IPS; $\alpha=.89$ for INPS) establishing the internal consistency of the items loaded to each dimension (Nunnally \& Bernstein, 1994) (Table 5).

Table 5: Exploratory factor analysis results

\begin{tabular}{|c|c|c|c|c|c|c|}
\hline Dimension & $\begin{array}{l}\text { Factor } \\
\text { Loadings }\end{array}$ & Eigenvalue & $\begin{array}{c}\% \text { of } \\
\text { Variance* }\end{array}$ & $\begin{array}{c}\text { Cronbach's } \\
\alpha\end{array}$ & KMO & $\begin{array}{l}\text { Bartlett's } \\
\text { test of } \\
\text { Sphericity }\end{array}$ \\
\hline $\begin{array}{l}\text { First } \\
\text { (INPS) }\end{array}$ & $\begin{array}{l}.864 \\
.830 \\
.884 \\
.888\end{array}$ & 3.466 & 37.97 & .891 & \multirow{2}{*}{.831} & \multirow{2}{*}{$\begin{array}{c}\mathrm{p}<.001 \\
\text { Approx. } \\
\text { Chi- } \\
\text { square= } \\
2536,216 \\
\text { df=28 }\end{array}$} \\
\hline $\begin{array}{l}\text { Second } \\
\text { (IPS) }\end{array}$ & $\begin{array}{l}.855 \\
.867 \\
.874 \\
.837\end{array}$ & 2.553 & 37.26 & .881 & & \\
\hline
\end{tabular}

Notes: IPS: Importance attached to participant sharing; INPS: Importance attached to non-participant sharing. *Total variance explained is $75.23 \%$.

598

599

600

601

602

603

604

605

606

607

608

609

610

611

612

613

614

\subsubsection{Confirmatory research - Phase 3}

At this stage, confirmatory factor analysis (CFA) was conducted in order to validate the nature of the ISMS construct and its dimensionality based on the EFA results. The aim here is to corroborate the two-dimensional structure of the ISMS scale and to establish convergent and discriminant validity. Therefore, the ISMS scale was first examined through CFA by using the maximum likelihood method in IBM AMOS 23.0. Here, the findings provided evidence of unidimensionality. The chi-square of this model was significant $\left(\chi^{2}=79.566\right.$; $\mathrm{df}=$ $19 ; \chi^{2} / \mathrm{df}=4.188$ ), and the values of additional fit indices were acceptable (root mean square error of approximation [RMSEA] = .076; comparative fit index [CFI] = .98; normed fit index $[\mathrm{NFI}]=.97$; goodness of fit index $[\mathrm{GFI}]=.97)$ (Anderson, Gerbing \& Hunter, 1987).

The standardized loadings of each item on their intended constructs were significant and exceeded the minimum criterion (.50) (Hair et al., 2009). Convergent validity was established because all factor loadings were highly significant and the average variance extracted (AVE) values were $>.50$ within each dimension (Fornell \& Larcker, 1981). After confirming the measurement model, the ISMS scale was examined for convergent and discriminant validity. Discriminant validity represents "the extent to which a construct is truly 
distinct from other constructs by empirical standards. Thus, establishing discriminant validity implies that a construct is unique and captures phenomena not represented by other constructs in the model" (Hair et al., 2014, p.104). We assessed discriminant and convergent validity in four ways. First, we confirmed that the square roots of the AVE of all constructs were larger than all other cross-correlations. Second, we confirmed that all AVEs were $>.50$. Third, the correlations among all constructs were identified as being distinct from each other. Fourth, all underlying items showed the highest loadings on their intended constructs, with all factor loadings $>.60$ (with significant $t$-values). Thus, all constructs hold adequate convergent and discriminant validity (Table 6 and Appendix 3).

Table 6. CFA Results

\begin{tabular}{ccccccc}
\hline Dimension & Items & $\begin{array}{c}\text { Std. Factor } \\
\text { Loadings }\end{array}$ & $\mathrm{t}$ & AVE & CR & Correlation \\
\hline \multirow{6}{*}{ INPS } & INPS1 & .82 & *Fixed & & & \\
& INPS2 & .74 & 18.781 & .67 & .89 & \\
& INPS3 & .87 & 22.784 & & & .18 \\
& INPS4 & .86 & 22.697 & & & $(.03)^{* *}$ \\
\multirow{6}{*}{ IPS } & IPS3 & .82 & *Fixed & & & \\
& IPS4 & .81 & 20.625 & .66 & & \\
& IPS5 & .84 & 21.733 & .68 & & \\
& IPS6 & .77 & 19.593 & & & \\
\hline
\end{tabular}

626

627

628

629

630

631

632

633

634

635

636

637

638

639

640

641

642

643

644

645

646

647

648

649

650

651

652

653

654

655

Notes: *Parameter fixed at 1.0 during ML estimation **Squared correlations between constructs are in parentheses. IPS: Importance attached to participant sharing; INPS: Importance attached to non-participant sharing.

\subsubsection{Common method bias}

In controlling for CMB, the two-factor and single-factor models were compared via chisquare tests, which demonstrated that the former was superior to the latter $\left(\Delta \chi^{2}=1130.2 ; \Delta \mathrm{df}=\right.$ $1, \mathrm{p}<.01)$. Therefore, common method bias was not a concern for this study, further supporting the two-dimensional structure.

\subsubsection{Nomological and predictive validity}

Nomological validity is the degree to which a construct acts as expected in theory (Bagozzi, 1980). To establish nomological validity, the relationship between the dimensions of ISMS and destination awareness were assessed using SEM. The results indicate that the 'goodnessof-fit' indices were acceptable $\left(\chi^{2}=219.594 ; \mathrm{df}=62 ; \chi^{2} / \mathrm{df}=3.542 ; \mathrm{CFI}=.96\right.$; TLI= .95; $\mathrm{NFI}=.95$; GFI $=.94$; RMSEA $=.068$ ) (Hair et al., 2003). Further, the findings also demonstrate that both IPS ( $\beta=.49, \mathrm{t}=10.153)$ and INPS $(\beta=.17, \mathrm{t}=3.971)$ significantly impacted upon destination awareness, explaining around $30 \%$ of the variance. Therefore, both $\boldsymbol{H}_{1}$ and $\boldsymbol{H}_{2}$ were supported. The model also held satisfactory explanatory power, further reinforcing nomological validity. The SRMR value was also taken into account when controlling for predictive validity (Taheri et al., 2017). As the SRMR value (.0440) was $<.05$, predictive validity was met (Hair et al., 2013).

\subsubsection{Cross-validation of scale}

We first examined whether gender (a demographical feature likely to stimulate significant differences) resulted in differentiation in the measurement scale. Second, as the measurement scale was applied to tourists from different cultures, invariance tests were conducted in order to investigate whether all respondents understood the items appropriately. For the comparison of the 'gender sub-sample', a configural invariance model was developed $\left(\chi^{2}=117.6 ; \mathrm{df}=38\right.$; $\chi^{2} / \mathrm{df}=3.096 ; \mathrm{CFI}=.97$; TLI=.96; NFI=.96; GFI=.95; RMSEA=.062) (Hair et al., 2003). This 
model was compared with the metric invariance model via chi-square difference test. The chisquare difference between the configural and metric invariance model was found to be nonsignificant for gender $(\Delta \chi 2(6)=11.5, p>.01)$. Later, to establish whether scalar invariance was supported, the metric invariance model was compared to the scalar invariance model. The result of the chi-square difference test demonstrated no significant difference between the two models $(\Delta \chi 2(8)=17.9, \mathrm{p}>.01)$.

The authors paid specific attention to whether respondents from different language groups (Turkish, German, Russian, and English) understood the questionnaire in the same way. In doing so, the configural invariance model was examined. Having confirmed that the configural invariance model was supported $\left(\chi^{2}=197.5 ; \mathrm{df}=76 ; \chi^{2} / \mathrm{df}=2.598 ; \mathrm{CFI}=.95\right.$; TLI= .93 ; NFI=.93; GFI=.92; RMSEA= .054), the metric invariance model was again investigated. The results indicate that the metric invariance model was fully supported $(\Delta \chi 2(18)=27.3$, $p>.01)$. Moreover, the scalar invariance model was examined. The chi-square difference between the metric and scalar invariance models was found to be non-significant $(\Delta \chi 2(24)=$ 41.3, $p>.01$ ). Additionally, in order to guarantee no differences between language groups (Turkish, German, Russian and English) subjected to the measurement invariance tests, $\chi 2$ tests were assessed between these groups and the respondents' demographical variables (gender, age, marital status, education and income levels).

As per the $\chi 2$ results, no significant differences between language groups and gender were found $(\chi 2=1.920 ; \mathrm{df}=3 ; p=.589)$; nor for age $(\chi 2=38.460 ; \mathrm{df}=18 ; p=.003)$, marital status $(\chi 2=6.107 ; \mathrm{df}=3 ; \mathrm{p}=.107)$, education $(\chi 2=21.530 ; \mathrm{df}=15 ; p=.121)$ or income level $(\chi 2=13.608$; $\mathrm{df}=12 ; p=.326)$. Accordingly, the distribution between the mentioned demographical characteristics and language groups is not disproportionate (), and did not skew the results (Oh \& Hsu, 2014). In short, the two-dimensional ISMS scale is consistent as its metric and scalar variance models are supported across both gender and language groups.

\subsubsection{Comparison of scale constructs}

The ISMS scale's one-factor model, the two-dimensional first-order model, and the twodimensional second-order model were compared. In doing so, RMSEA ( Hair et al., 2013), Akaike information criterion (AIC) and consistent AIC (CAIC) (Hair et al., 2013) were taken into consideration. As per Table 7, the one-factor model's goodness-of-fit indices were not acceptable, whereas those of the two-dimensional first-order and two-dimensional secondorder models were acceptable. The standard factor loading of the INPS dimension of the twodimensional second-order construct was $<.50$. Therefore, this may prohibit convergent validity. More specifically, when ISMS is considered as a second-order structure, the results indicate that the correlation between IPS and INPS dimensions is insufficient. Conversely, if all statements are made under a single dimension, the model fit indices are not appropriate. Therefore, it is likely that an incorrect or misleading measurement will be made. As such, the use of a structure in which these two dimensions are evaluated separately but in the same measurement model (i.e., two-dimensional first-order) is preferable, as it provides results that are more accurate. Thus, the two-dimensional first-order model is stronger.

Table 7. Summary of model comparisons

\begin{tabular}{lcccccc}
\hline \multicolumn{1}{c}{ Model } & $\chi^{2}$ & df & RMSEA & CFI & AIC & CAIC \\
\hline One-factor & 1315.7 & 20 & .342 & .49 & 1347.7 & 1432.7 \\
Two-dimensional first-order & 79.5 & 19 & .076 & .98 & 113.5 & 203.9 \\
Two-dimensional second-order & 79.5 & 19 & .076 & .98 & 113.5 & 203.9 \\
\hline
\end{tabular}




\subsection{Replication in another country (Phase 4)}

701 Following Hinkin et al. (1997), the generalizability of the model was tested with tourists who visited Glasgow, with confirmatory factor analysis first conducted. Next, internal consistency reliability and construct validity were examined. According to the CFA results, the overall fit of the measurement model was satisfactory: $\chi 2=80.001(\mathrm{df}=19, p<.001)$, RMSEA $=.072$, $\mathrm{CFI}=.98, \mathrm{NFI}=.97)$. Composite reliability values surpassed .87 , exceeding the recommended threshold (.60) (Bagozzi \& Yi, 1988). Therefore, the items used to assess each construct were reliable and internally consistent. Further, convergent validity was assessed with the factor loadings in the measurement model. All confirmatory factor loadings exceeded .70, and all were significant $(p<.05)$. Likewise, the average variance extracted (AVE) from all constructs exceeded the recommended (.5) threshold (IPS=.64; INPS=.64) (Fornell \& Larcker, 1981). Therefore, convergent validity was met. Discriminant validity was assessed by comparing the AVE values with the squared correlation between the two constructs. These AVE values were greater than the squared correlations between both constructs, supporting discriminant validity (Fornell \& Larcker, 1981). The Chi-square difference test was used to test for CMB; the two-factor model was compared with the single-factor model. The chi-square tests also demonstrated that the two-factor model was superior to the single-factor model $\left(\Delta \chi^{2}=\right.$ 1192.72; $\Delta \mathrm{df}=1, p<.01)$. Therefore, common method bias was not a concern for this study and the two-dimensional structure was further supported. Correlation matrix results are presented in Appendix 4.

Finally, in order to evaluate nomological and predictive validity, SEM was implemented. The standardized path coefficient of the relationship between IPS and destination awareness was .46 $(\mathrm{t}=9.820 ; p<.01)$, suggesting that IPS is a significant predictor of destination awareness. Further, INPS has a significant positive effect on destination awareness $(\beta=.17 ; \mathrm{t}=4.110 ; p<.01)$, and both IPS and INPS held satisfactory explanatory power for destination awareness $\left(R^{2}=.27\right)$, supporting nomological validity. The SRMR value was examined in controlling for predicate validity. The recommended value for SRMR is $<.05$, demonstrating the predictive validity of the newly developed ISMS scale (.0439).

\section{Discussion and conclusions}

CGC across social media platforms is critically important for tourism businesses. However, it is likely that potential consumers prescribe different levels of importance to content generated by others depending on where, how, and why it is shared. Therefore, it is necessary to investigate and assess different types of consumer-generated content in order to better understand and manage the influence CGC can have on organizations. Prior studies highlight the shortcomings of existing CGC classifications generally (O’Hern \& Kahle, 2013; Shao, 2009), with this study responding to the need for a new measurement scale to assess the ISMS classification in the domain of tourism marketing. In doing so, this study followed a rigid multi-step, mixed-method scale development procedure (Churchill, 1979; Taheri et al., 2018). As no prior research has focused on the development of an ISMS scale, this study serves as a nascent assessment of this concept, contributing significantly to both theory and practice.

Concerning social media, extant literature typically attempts to measure consumers' engagement behaviors and involvement levels. For instance, Mirbagheri and Najmi (2019) emphasize that consumers are considered active on social media based on their attention (cognitive engagement), interest and enjoyment (affective engagement), and participation (behavioral engagement). Similarly, Hollebeek et al. (2014) investigated the measurement of consumers' brand engagement behaviors in social media and emphasized that engagement can be examined and measured within the framework of cognitive processing, affection, and activation. A 'brand' (or indeed the social media activities of a brand) typically serves as the 
focal point of these studies. Yet, this study contends that the presence of a specific stimulant is not essential. Consumers can generate content with their own motives. As such, it differs content-generation process itself. Further, research contends that social media involvement measures the extent to which individuals attach importance to social media more generally (Amaro, Duarte \& Henriques, 2016). However, in this study, the importance attached to CGC on social media was measured, as opposed to the overall importance consumers attach to social media platforms.

Nonetheless, the newly developed ISMS scale is similar to Bearden, Netemeyer, and Teel's (1989) 'susceptibility to interpersonal influence' scale in some ways, namely as both recognize how the behavior and actions of one party can shape those of others. Further, IPS is similar to what Bearden et al. (1989) classes as an informational dimension, whereas INPS echoes the normative dimensions of the 'susceptibility to interpersonal influence' scale. However, it is crucial to note that Bearden et al.'s (1989) work measures phenomena beyond that of our newly developed ISMS scale. More precisely, it considers individuals' preference and purchase intentions via the aforementioned normative and informational dimensions. However, the newly developed ISMS scale only measures the level of importance that potential consumers attached to CGC. In other words, the possible elements that might shape purchasing intention are emphasized rather than focusing on direct purchasing trends. Moreover, the importance of CGC was classified in this study, alongside whether different levels of importance could result in different impacts.

\subsection{Theoretical implications}

The results indicate that CGC can be categorized in two ways and that CGC is composed of two dimensions: (1) participant sharing and (2) non-participant sharing. More specifically, with the aid of the newly developed ISMS scale, it is possible to examine the level of importance that existing and potential consumers attach to content generated by other consumers through the two approaches to CGC presented in this study. Further, the results suggest that the INPS dimension proposed in this study exhibits partial similarity with those emerging from prior research. For example, elements of INPS echo 'spontaneous' CGC (Kiecker \& Cowles, 2002), 'organic eWoM' (Kulmala et al., 2013), 'simplerecommendations' (Park and Lee, 2008), and the 'implicit' dimension discussed by Ebermenn et al. (2011). Nevertheless, the main function of the dimensions mentioned in these studies focuses on information giving and the way this information is emotion-centered, with emphasis on the fact that it is manifest in a spontaneous way. Therefore, while non-participant sharing exhibits some similar characteristics with these extant dimensions in terms of emotion and spontaneity, it is assumed that the principal underlying goal of those engaged in nonparticipant sharing is not solely the sharing of the information itself.

As the IPS dimension presented in this study also includes content created with direct or indirect organizational involvement, it exhibits a degree of similarity to the 'attribute value dimension' highlighted by Park and Lee (2008). Further, the characteristics of the aforementioned IPS dimension are somewhat similar to the 'quasi-spontaneous', 'third partysponsored', and 'corporate-sponsored' dimensions discussed by Kicker and Cowles (2002); the 'explicit' dimension studied by Ebermenn et al. (2011); and 'amplified eWoM' (Bore et al., 2017). Thus, while IPS and INPS cover and combine a range of dimensions discussed throughout extant literature, theoretical value also stems from the clarity that this study brings to contemporary CGC classification.

To this end, the importance attached to participant and non-participant sharing may differ based on the motives of those engaging with this content. In particular, content- 
followers may perceive that content shared without commercial purpose is more interesting and attractive (Chen et al., 2014). Organizations can offer different types of discounts to consumers who have experienced their offerings. Thus, consumers may be more inclined to content followers do not know whether consumers crete content with promotional purposes. In other words, non-participant sharing, compared to participant sharing, is more likely to affect potential tourists' behavior because it surfaces without the motive to provide any information to the organization. As in social identity and social learning theories, individuals typically pursue experiences that others have undergone, particularly if they perceive these experiences as being positive, enjoyable, aspirational and/or worthy of appreciation. For this reason, INPS can encourage potential consumers to pursue the same experiences as those they have seen shared online. Supporting this, Sedera et al. (2017) emphasized that potential tourists could opt to undertake similar experiences because of CGC's social influence. Similarly, Narangajavana et al. (2017) suggested that exposure to social media content considerably affects tourists' destination expectations.

Finally, participant sharing, unlike non-participant sharing, emerges on platforms where the organization is involved (either directly or indirectly). Consumers who attach importance to participant-shared content typically do so due to the information it provides them, particularly when they have explicitly searched for this information. Nonetheless, platforms such as official websites, fan websites relating to organizations and brands, and third-party aggregators (e.g., TripAdvisor), which enable people to review organizations and to gather information via CGC present this information in different ways. In this sense, Gretzel and Yoo (2008) revealed that tourists best benefit from other consumers' reviews on third party platforms, satisfying their desire to engage in information seeking and information gaining. As a result, one would anticipate that further importance should be attached to participant sharing as opposed to non-participant sharing.

\subsection{Practical implications}

The results indicate that managers and social media marketers should pay attention to both participant sharing and non-participant sharing in order to develop a robust and nuanced understanding of the role of CGC. The proposed participant sharing and non-participant sharing scales provide a valuable instrument to help managers and social media marketers evaluate CGC more analytically. In other words, the newly developed scale provides instructions to managers and social media marketers (alongside website designers) to interpret the differences between participant sharing and non-participant sharing in different contexts. This study therefore provides an actionable tool that can be used to gauge their customers' experiences when interacting with CGC, and can consequently help in designing effective communication strategies.

To increase the efficiency and effectiveness of participant sharing, and to become more adept at influencing potential consumers seeking information from social media platforms, practitioners should first encourage past consumers to generate content through their own official social media platforms. A clear, hierarchical system (e.g., attributing titles to experienced consumers) should be employed in order to prevent this CGC from being perceived as insincere, unsubstantiated, or fake. Practitioners should encourage consumers to generate complementary content in conjunction with the experiences that they have undertaken. Further, consumers who share photographs and videos should be rewarded in different ways (e.g., granting a discount for their next holiday) in order to encourage the widespread sharing of more visual forms of CGC. In line with this, Yoo and Gretzel (2012) found that, in 2008, consumers showed interest in photograph and video content at the level of $50.6 \%$ and $14.2 \%$, respectively. However, these rates increased to $54.9 \%$ and $23.9 \%$ 
respectively in 2010. As such, CGC containing photographs and videos not only helps to portray the functional and emotional elements of tourism destinations and experiences to other (potential) consumers, but also acts as an important supplementary information source. By encouraging existing consumers to share such visual content (Lo et al., 2011), tourism organizations can lessen the impact of language fluency on the effectiveness of CGC. As tourism is a global industry, unconstrained by nationality or language, such CGC is better placed to serve as universally understandable sources of information for prospective international consumers.

As non-participant sharing (unlike participant sharing) is not a controllable form of CGC, it is not easy for practitioners to direct or curate it. This content emerges on an individual's personal social media profiles, or in those controlled by their friends. Nonetheless, organizations should encourage individuals to generate this type of content. Here, it is important for tourism organizations to curate their offering in a way that is suitably distinct, enjoyable, and gratifying in order to satisfy consumer expectations and encourage them to share CGC. Tourism organizations should recognize that individuals often aim to gain social status by participating in unique experiences and many aim to achieve this via the content that they share across their preferred social media platforms (Lee \& Ma, 2012). Therefore, organizations must recognize the expectations of their customers. Accordingly, they must provide positive experiences and enable consumers to obtain positive feelings. By doing so, consumers may be more likely to share their positive tourism experiences in line with their own hedonic motives (e.g. prestige seeking, enhancing social networks, etc.). Nonetheless, while it is difficult to control non-participant sharing, as individuals are more likely to be motivated by hedonic motivation, tourism organizations can still cater to their desires by providing a suitably interesting, unusual, and rewarding consumption forum through which to stimulate positive CGC. More explicitly, if a tourist gains hedonic benefit from the destinations, events, sites (and experiences undertaken therein) that they visit, they may be more inclined to share such experiences across their own, and their friends', social media accounts - allowing tourism organizations to take advantage of non-participant sharing in a more nuanced manner.

Finally, it may be beneficial to focus more closely on social network platforms. Here, the hedonic benefits of sharing content (e.g., obtaining social status, prestige) may be more likely to emerge from 'likes' within an individuals' immediate/close environment. This is more likely on personal social media platforms than on CGC shared on other, third-party websites. Accordingly, organizations should encourage tourists to generate and share content about their experience of the organization's products or services. However, organizations must not interfere in the design of the content being shared; merely encourage consumers to do so. For instance, consumers should be encouraged to generate and share content on their own or friends' social media accounts with organization-specific hashtags. Since this sharing type is non-participant, it may be perceived by other potential consumers as more sincere, reliable, and credible. By following up on their own hashtags, organizations may be able to offer promotions to previous customers. In doing so, the volume of content shared, and the associated benefits of brand awareness, may increase.

\section{Limitations and future research}

As with all scholarship, this study is not bereft of limitations. First, the scale developed in the study was examined solely within the context of tourism. Testing the scale in different sectors could allow for further generalization of the findings. Second, the respondents were not asked to identify which social media platforms they used. Instead, they were asked to consider all social media platforms more generally. However, each platform may have unique characteristics, and this may subsequently differentiate the level of importance placed by 
consumers on IPS and INPS. Future studies should therefore compare CGC shared on social networks underpinned by friendship and personal connections (e.g., Facebook and Instagram) with CGC shared on third-party websites typically lacking this core interpersonal component (e.g., TripAdvisor), as important supplementary findings may emerge. Third, the research sample was inherently non-generalizable. Only tourists fluent in German, Russian, Turkish, or English were included in this study. However, many of those using social media are from China or are fluent in French (GWI, 2014). Therefore, we encourage colleagues to develop future studies in which respondents from alternate countries serve as the sample in order to dilute the geographic specificity of this study. Further, the participants were approached based on their availability and through convenience sampling; future studies should be designed with a more purposeful sampling strategy in mind.

This study focuses on the motives underpinning CGC, alongside the importance of where shared content is manifest. As such, CGC was classified as participant and nonparticipant sharing throughout, with attention paid to its utilitarian or hedonic antecedents, and whether it emerges on individuals' or organizations' social media accounts. However, the decision to characterize CGC as participant and non-participant sharing remains an assumption, with the possibility that CGC could be classified differently when individuals: (1) hold greater hedonic motives while generating content (directly or indirectly) on organizations' social media accounts, or (2) have a more utilitarian motive, yet generate content on their own social media accounts. As such, the stimulus behind, and importance attached to, content shared by consumers under these conditions may remain ambiguous, with these sharing behaviors somewhat overlooked by the newly developed ISMS scale. Thus, depending on their focus, future studies may wish to first explore different classifications of CGC cognizant of these issues. Finally, contextual variables could moderate and/or mediate the effects of IPS and INPS on destination awareness. Future studies may also wish to investigate this. Despite the acknowledged shortcomings, the current study represents a necessary step forward in CGC research that benefits organizations as well as potential tourists. 
Abrantes, J., Seabra, C., Raquel Lages, C., \& Jayawardhena, C. (2013). Drivers of in-group and out-of-group electronic word-of-mouth (eWoM). European Journal of Marketing, 47(7), 1067-1088.

Alsufyan, N.K., \& Aloud, M. (2017). The state of social media engagement in Saudi universities. Journal of Applied Research in Higher Education, 9(2), 267-303.

Alvarez, M.D. (2010). Marketing of Turkey as a tourism destination. Anatolia, 21(1), 123138.

Amaro, S., Duarte, P., \& Henriques, C. (2016). Travelers' use of social media: A clustering approach. Annals of Tourism Research, 59, 1-15.

Anderson, J.C., Gerbing, D.W., \& Hunter, J.E. (1987). On the assessment of unidimensional measurement: Internal and external consistency, and overall consistency criteria. Journal of Marketing Research, 432-437.

Arndt, J. (1967). Role of product-related conversations in the diffusion of a new product. Journal of Marketing Research, 4(3), 291-295.

Bagozzi, R.P. (1980). Causal models in marketing. New York: Wiley.

Bagozzi, R.P., \& Yi, Y. (1988). On the evaluation of structural equation models. Journal of the Academy of Marketing Science, 16(1), 74-94.

Bandura, A. (1977). Social learning theory. New Jersey: Prentice-Hall.

Bearden, W.O., \& Rose, R.L. (1990). Attention to social comparison information: An individual difference factor affecting consumer conformity. Journal of Consumer Research, 16(4), 461-471.

Bearden, W.O., Netemeyer, R.G., \& Teel, J.E. (1989). Measurement of consumer susceptibility to interpersonal influence. Journal of Consumer Research, 15(4), 473481.

Bilgicer, T., Jedidi, K., Lehmann, D.R., \& Neslin, S.A. (2015). Social Contagion and Customer Adoption of New Sales Channels, Journal of Retailing, 91 (2) 254-271.

Bore, I., Rutherford, C., Glasgow, S., Taheri, B., \& Antony, J. (2017). A systematic literature review on eWOM in the hotel industry: Current trends and suggestions for future research. Hospitality \& Society, 7(1), 63-85.

Bruhn, M., Schoenmueller, V., \& Schäfer, D. B. (2012). Are social media replacing traditional media in terms of brand equity creation?. Management Research Review, 35(9), 770-790.

Bulut, Z.A., \& Doğan, O. (2017). The ABCD typology: Profile and motivations of Turkish social network sites users. Computers in Human Behavior, 67, 73-83.

Burgess, S., Sellitto, C., Cox, C., \& Buultjens, J. (2011). Trust perceptions of online travel information by different content creators: Some social and legal implications. Information Systems Frontiers, 13(2), 221-235.

Chae, H., \& Ko, E. (2016). Customer social participation in the social networking services and its impact upon the customer equity of global fashion brands. Journal of Business Research, 69(9), 3804-3812.

Chen, C.H., Nguyen, B., Klaus, P.P., \& Wu, M.S. (2015). Exploring electronic word-ofmouth (eWoM) in the consumer purchase decision-making process: the case of online holidays-evidence from United Kingdom (UK) consumers. Journal of Travel \& Tourism Marketing, 32(8), 953-970.

Chen, C.Y., Chen, T.H., Chen, Y.H., Chen, C.L., \& Yu, S.E. (2013). The spatio-temporal distribution of different types of messages and personality traits affecting the eWoM of Facebook. Natural hazards, 65(3), 2077-2103. 
Chen, Y.C., Shang, R.A., \& Li, M.J. (2014). The effects of perceived relevance of travel blogs' content on the behavioral intention to visit a tourist destination. Computers in Human Behavior, 30, 787-799.

Chu, S.C., \& Kim, Y. (2011). Determinants of consumer engagement in electronic word-ofmouth (eWoM) in social networking sites. International Journal of Advertising, 30(1), 47-75.

Chung, N., Han, H., \& Koo, C. (2015). Adoption of travel information in user-generated content on social media: the moderating effect of social presence. Behaviour \& Information Technology, 34(9), 902-919.

Churchill Jr, G.A. (1979). A paradigm for developing better measures of marketing constructs. Journal of Marketing Research, 64-73.

Cohen, J.B. (1983). Involvement and You-1000 great ideas. Advances in Consumer Research, 10, 325-328.

Cox, D.F., \& Bauer, R.A. (1964). Self-confidence and persuasibility in women. Public Opinion Quarterly, 453-466.

Dedeoğlu B.B. (2016). The Relationship between Social Media, Involvement and Destination Brand Equity. Doctoral Dissertation, Institute of Social Sciences, Akdeniz University, Antalya, Turkey.

DeVellis, R.F. (2003). Scale development: Theory and applications (Second Ed.). Thousand Oaks, California, USA: Sage Publications.

DeWalt, K. M., \& DeWalt, B. R. (2011). Participant observation: A guide for fieldworkers. Plymouth, UK: Altamira Press.

Dolan, R., Conduit, J., Fahy, J., \& Goodman, S. (2016). Social media engagement behaviour: a uses and gratifications perspective. Journal of Strategic Marketing, 24(3-4), 261277.

Ebermann, J., Stanoevska-Slabeva, K., \& Wozniak, T. (2011). Influential factors of recommendation behaviour in social network sites-an empirical analysis. In European Conference on Information Systems (ECIS) (p. 259). AIS Electronic Library.

Eley, B. \& Tilley, S. (2009). Online Marketing Inside Out. Australia: SitePoint Pty Ltd.

Ferns, B.H., \& Walls, A. (2012). Enduring travel involvement, destination brand equity, and travelers' visit intentions: A structural model analysis. Journal of Destination Marketing \& Management, 1(1), 27-35.

Fornell, C., \& Larcker, D.F. (1981). Evaluating structural equation models with unobservable variables and measurement error. Journal of Marketing Research, 39-50.

Foroudi, P. (2019). Influence of brand signature, brand awareness, brand attitude, brand reputation on hotel industry's brand performance, International Journal of Hospitality Management, 76, 271-285.

Fu, P.W., Wu, C.C., \& Cho, Y.J. (2017). What makes users share content on facebook? Compatibility among psychological incentive, social capital focus, and content type. Computers in Human Behavior, 67, 23-32.

Gannon, M.J., Baxter, I.W., Collinson, E.,...\& Maxwell-Stuart, R. (2017). Travelling for Umrah: destination attributes, destination image, and post-travel intentions. The Service Industries Journal, 37(7-8), 448-465.

Gensler, S., Völckner, F., Liu-Thompkins, Y., \& Wiertz, C. (2013). Managing brands in the social media environment. Journal of Interactive Marketing, 27(4), 242-256.

Gómez, M., Lopez, C., \& Molina, A. (2015). A model of tourism destination brand equity: The case of wine tourism destinations in Spain. Tourism Management, 51, 210-222.

Grace-Farfaglia, P., Dekkers, A., Sundararajan, B., Peters, L., \& Park, S.H. (2006). Multinational web uses and gratifications: Measuring the social impact of online 
community participation across national boundaries. Electronic Commerce Research, 6(1), 75-101.

Gretzel, U., \& Yoo, K.H. (2008). Use and impact of online travel reviews. In P. O'Connor, W. Höpken, \& U. Gretzel (eds), Information and communication technologies in tourism 2008 (pp. 35-46). Austria: Springer-Verlag.

Gursoy, D., \& Gavcar, E. (2003). International leisure tourists' involvement profile. Annals of Tourism Research, 30(4), 906-926.

GWI, (2014). Global Web Index, Active Usage: Social Platforms: Demographic and trend data for active usage of social media platforms. https://www.globalwebindex.net/reports Last accessed 10.05.2015.

Hair J.F., Hult, G.T.M., Ringle, C., \& Sarstedt, M. (2014). A primer on partial least squares structural equation modeling (PLS-SEM). London: Sage Publications.

Hair, J.F., Black, W.C., Babin, B.J. \& Anderson, R.E. (2013). Multivariate Data Analysis: Pearson New International Edition (Seventh Ed.). Harlow: Pearson Higher Ed.

Hays, S., Page, S.J., \& Buhalis, D. (2013). Social media as a destination marketing tool: its use by national tourism organisations. Current Issues in Tourism, 16(3), 211-239.

Heinonen, K. (2011). Consumer activity in social media: Managerial approaches to consumers' social media behavior. Journal of Consumer Behaviour, 10(6), 356-364.

Herrero, Á., San Martín, H., \& Hernández, J.M. (2015). How online search behavior is influenced by user-generated content on review websites and hotel interactive websites. International Journal of Contemporary Hospitality Management, 27(7), 1573-1597.

Hewer, P., Gannon, M., \& Cordina, R. (2017). Discordant fandom and global football brands:'Let the people sing'. Journal of Consumer Culture, 17(3), 600-619.

Hinkin, T.R., Tracey, J.B., \& Enz, C.A. (1997). Scale construction: Developing reliable and valid measurement instruments. Journal of Hospitality \& Tourism Research, 21(1), 100-120.

Hollebeek, L. D., Glynn, M. S., \& Brodie, R. J. (2014). Consumer brand engagement in social media: Conceptualization, scale development and validation. Journal of Interactive Marketing, 28(2), 149-165.

Jellison, J.M., \& Gentry, K.W. (1978). A self-presentation interpretation of the seeking of social approval. Personality and Social Psychology Bulletin, 4(2), 227-230.

Kamboj, S., \& Sarmah, B. (2018). Construction and validation of the customer social participation in brand communities scale. Internet Research, 28(1), 46-73.

Kang J. (2018). Effective marketing outcomes of hotel Facebook pages: The role of active participation and satisfaction. Journal of Hospitality and Tourism Insights 1(2), 106120.

Keller, K. (2013). Strategic Brand Management: Building, Measuring and Managing Brand equity (Fourth ed.). Edinburgh, UK: Pearson Higher Ed.

Keller, K.L. (1993). Conceptualizing, measuring, and managing customer-based brand equity. The Journal of Marketing, 1-22.

Kiecker, P., \& Cowles, D. (2002). Interpersonal communication and personal influence on the Internet: A framework for examining online word-of-mouth. Journal of Euromarketing, 11(2), 71-88.

Kim, A.J., \& Johnson, K.K. (2016). Power of consumers using social media: Examining the influences of brand-related user-generated content on Facebook. Computers in Human Behavior, 58, 98-108.

Kim, W., Jun, H.M., Walker, M., \& Drane, D. (2015). Evaluating the perceived social impacts of hosting large-scale sport tourism events: Scale development and validation. Tourism Management, 48, 21-32. 
1084

1085

1086

1087

1088

1089

1090

1091

1092

1093

1094

1095

1096

1097

1098

1099

1100

1101

1102

1103

1104

1105

1106

1107

1108

1109

1110

1111

1112

1113

1114

1115

1116

1117

1118

1119

1120

1121

1122

1123

1124

1125

1126

1127

1128

1129

1130

1131

1132

1133

Kladou, S., \& Kehagias, J. (2014). Assessing destination brand equity: An integrated approach. Journal of Destination Marketing \& Management, 3(1), 2-10.

Kline, R.B. (2011). Principles and Practice of Structural Equation Modeling, 3rd ed. Guilford Press. New York.

Kotler, P. \& Keller, K.L. (2012). Marketing management 14 (ed.). Upper Saddle River, New Jersey: Prentice Hall.

Krishnamurthy, S., \& Dou, W. (2008). Note from special issue editors: Advertising with usergenerated content: A framework and research agenda. Journal of Interactive Advertising, 8(2), 1-4.

Kulmala, M., Mesiranta, N., \& Tuominen, P. (2013). Organic and amplified eWoM in consumer fashion blogs. Journal of Fashion Marketing and Management: An International Journal, 17(1), 20-37.

Lee, C.S., \& Ma, L. (2012). News sharing in social media: The effect of gratifications and prior experience. Computers in Human Behavior, 28(2), 331-339.

Lee, J.E., \& Watkins, B. (2016). YouTube vloggers' influence on consumer luxury brand perceptions and intentions. Journal of Business Research, 69(12), 5753-5760.

Litvin, S.W., Goldsmith, R.E., \& Pan, B. (2008). Electronic word-of-mouth in hospitality and tourism management. Tourism Management, 29(3), 458-468.

Liu, J., Li, C., Ji, Y.G., North, M., \& Yang, F. (2017). Like it or not: The Fortune 500's Facebook strategies to generate users' electronic word-of-mouth. Computers in Human Behavior, 73, 605-613.

Lo, I. S., McKercher, B., Lo, A., Cheung, C., \& Law, R. (2011). Tourism and online photography. Tourism Management, 32(4), 725-731.

Malik, A., Dhir, A., \& Nieminen, M. (2016). Uses and gratifications of digital photo sharing on Facebook. Telematics and Informatics, 33(1), 129-138.

Mariani, M., Ek Styven, M., \& Ayeh, J. K. (2019). Using Facebook for travel decisionmaking: an international study of antecedents. International Journal of Contemporary Hospitality Management, 31(2), 1021-1044.

Miniard, P.W., \& Cohen, J.B. (1983). Modeling Personal and Normative Influences on Behavior. Journal of Consumer Research, 10 (September), 169-180.

Mirbagheri, S., \& Najmi, M. (2019). Consumers' engagement with social media activation campaigns: Construct conceptualization and scale development. Psychology \& Marketing. https://doi.org/10.1002/mar.21185

Morosan, C. \& Bowen J.T. (2018). Analytic perspectives on online purchasing in hotels: A review of literature and research directions. International Journal of Contemporary Hospitality Management 30(1), 557-580.

Narangajavana, Y., Fiol, L.J.C., Tena, M.Á.M., Artola, R.M.R., \& García, J.S. (2017). The influence of social media in creating expectations. An empirical study for a tourist destination. Annals of Tourism Research, 65, 60-70.

Nunnally, J.C. \& Bernstein, I.H. (1994). Psychometric Theory (Third Ed.). New York: McGraw-Hill Inc.

O’Hern, M.S., \& Kahle, L.R. (2013). The empowered customer: User-generated content and the future of marketing. Global Economics and Management Review, 18(1), 22-30.

Oh, H., \& Hsu, C.H. (2014). Assessing equivalence of hotel brand equity measures in crosscultural contexts. International Journal of Hospitality Management, 36, 156-166.

Oh, S., Baek, H., \& Ahn, J. (2015). The effect of electronic word-of-mouth (eWoM) on mobile application downloads: an empirical investigation. International Journal of Mobile Communications, 13(2), 136-156.

Ozimek, P., Bierhoff, H-W., \& Hanke, S. (2018). Do vulnerable narcissists profit more from Facebook use than grandiose narcissists? An examination of narcissistic Facebook use 
in the light of self regulation and social comparison theory. Personality and Individual Differences, 124,168-177

Palmer, A., \& Koenig-Lewis, N. (2009). An experiential, social network-based approach to direct marketing. Direct Marketing: An International Journal, 3(3), 162-176.

Pan, L., Zhang, M., Gursoy, D., \& Lu, L. (2017). Development and validation of a destination personality scale for mainland Chinese travelers. Tourism Management, 59, 338-348.

Park, D.H., \& Lee, J. (2008). eWoM overload and its effect on consumer behavioral intention depending on consumer involvement. Electronic Commerce Research and Applications, 7(4), 386-398.

Perez-Vega, R., Taheri, B., Farrington, T., \& O’Gorman, K. (2018). On being attractive, social and visually appealing in social media: The effects of anthropomorphic tourism brands on Facebook fan pages. Tourism Management, 66, 339-347.

Pike, S., Bianchi, C., Kerr, G., \& Patti, C. (2010). Consumer-based brand equity for Australia as a long-haul tourism destination in an emerging market. International Marketing Review, 27(4), 434-449.

Podsakoff, P.M., MacKenzie, S.B., Lee, J.Y., \& Podsakoff, N.P. (2003). Common method biases in behavioral research: a critical review of the literature and recommended remedies. Journal of Applied Psychology, 88(5), 879.

Scherer, C. W., \& Cho, H. (2003). A social network contagion theory of risk perception. Risk Analysis: An International Journal, 23(2), 261-267.

Sedera, D., Lokuge, S., Atapattu, M., \& Gretzel, U. (2017). Likes-the key to my happiness: The moderating effect of social influence on travel experience. Information \& Management, 54(6), 825-836.

Shao, G. (2009). Understanding the appeal of user-generated media: a uses and gratification perspective. Internet Research, 19(1), 7-25.

Shao, C., \& Kwon, K. H. (2019). Clicks intended: An integrated model for nuanced social feedback system uses on Facebook. Telematics and Informatics, 39, 11-24.

Sigala, M. (2018). Implementing social customer relationship management: A process framework and implications in tourism and hospitality. International Journal of Contemporary Hospitality Management, 30(7), 2698-2726.

Soper, D.S. (2017). A-priori sample size calculator for structural equation models [Software]. Available from: www.danielsoper.com/statcalc. Last accessed 12.09.2017.

Sparks, B.A., Perkins, H.E., \& Buckley, R. (2013). Online travel reviews as persuasive communication: The effects of content type, source, and certification logos on consumer behavior. Tourism Management, 39, 1-9.

Stets, J.E., \& Burke, P.J. (2000). Identity theory and social identity theory. Social Psychology Quarterly, 63(3), 224-237.

Strack, F. (1999). Beyond dual-process models: Toward a flexible regulation system. Psychological Inquiry, 10(2), 166-169.

Su, L., Huang, Y., \& Hsu, M. (2018). Unraveling the impact of destination reputation on place attachment and behavior outcomes among Chinese urban tourists. Journal of Hospitality and Tourism Insights, 1(4), 290-308.

Tabachnick, B.G. \& Fidell, L.S. (2012). Using multivariate statistics (Sixth Ed.). NY, USA: Pearson Education.

Taheri, B., Gannon, M.J., Cordina, R., \& Lochrie, S. (2018). Measuring host sincerity: scale development and validation. International Journal of Contemporary Hospitality Management, 30(8), 2752-2772.

Taheri, B., Jafari, A., \& Okumus, B. (2017). Ceremonious politeness in consuming food in VFR tourism: scale development. The Service Industries Journal, 37(15-16), 948-967. 
Tajvidi, M., Wang, Y., Hajli, N., \& Love, P. E. (2017). Brand value Co-creation in social commerce: The role of interactivity, social support, and relationship quality. Computers in Human Behavior.

Tajfel, H., \& Turner, J.C. (1979). An integrative theory of intergroup conflict. In W. G. Austin \& S. Worchel (Eds.), in The social psychology of intergroup relations (pp. 3347). CA: Brooks-Cole Publishing.

TripAdvisor (2019). Investor Relations. http://ir.tripadvisor.com/ [Accessed: 09.03.2019].

Valkenburg, P.M., Peter, J., \& Schouten, A. P. (2006). Friend networking sites and their relationship to adolescents' well-being and social self-esteem. CyberPsychology \& Behavior, 9(5), 584-590.

VisitScotland (2016). Tourism in Scotland's Regions 2015 (Updated October 2016). http://www.visitscotland.org [Accessed: 14.12.2017].

VisitScotland (2017). The key facts on tourism in 2016 (September 2017). http://www.visitscotland.org [Accessed: 19.01.2019].

Webb, H.J., \& Zimmer-Gembeck, M.J. (2014). The role of friends and peers in adolescent body dissatisfaction: A review and critique of 15 years of research. Journal of Research on Adolescence, 24(4), 564-590.

Weisfeld-Spolter, S., Sussan, F., \& Gould, S. (2014). An integrative approach to eWoM and marketing communications. Corporate Communications: An International Journal, 19(3), 260-274.

Wen, J., Meng, F., Ying, T., Qi, H., \& Lockyer, T. (2018). Drug tourism motivation of Chinese outbound tourists: Scale development and validation, Tourism Management, 64, 233-244.

Westland, J.C. (2012). Erratum to Lower bounds on sample size in structural equation modeling [Electron. Commerce Res. Appl. 9 (6) (2010) 476-487]. Electronic Commerce Research and Applications, 11(4), 445.

Wu, P.C., \& Wang, Y.C. (2011). The influences of electronic word-of-mouth message appeal and message source credibility on brand attitude. Asia Pacific Journal of Marketing and Logistics, 23(4), 448-472.

Xiang, Z., \& Gretzel, U. (2010). Role of social media in online travel information search. Tourism Management, 31(2), 179-188.

Yan, J., Jiang, Q., Adam, Z., \& Fu, C. (2011). The role of eWoM (electronic word-of-mouth) message format and direction impact on perceived informativeness of prospective browsing online consumers. Service Systems and Service Management, 1-5.

Yoo, K.H, \& Gretzel, U. (2012). Use and Creation of Social Media by Travellers. in Social Media in Travel, Tourism and Hospitality: Theory, Practive and Cases, Editor: Sigala, Marianna, Christou, Avangelos and Gretzel, Ulrike (p.189-205). Burlington, VT, USA: Ashgate Pub.

Zeng, B., \& Gerritsen, R. (2014). What do we know about social media in tourism? A review. Tourism Management Perspectives, 10, 27-36.

Zhang, J., \& Lee, W.N. (2012). Exploring the influence of cultural value orientations on motivations of electronic word-of-mouth communication. Journal of Internet Commerce, 11(2), 117-138.

Zheng, K., Padman, R., Krackhardt, D., Johnson, M. P., \& Diamond, H. S. (2010). Social networks and physician adoption of electronic health records: insights from an empirical study. Journal of the American Medical Informatics Association, 17(3), 328336. 